\title{
Health promotion during midlife: The influence of internal health locus of control and future time perspective
}

\author{
Sarah T. Stahl \\ West Virginia University
}

Follow this and additional works at: https://researchrepository.wvu.edu/etd

\section{Recommended Citation}

Stahl, Sarah T., "Health promotion during midlife: The influence of internal health locus of control and future time perspective" (2009). Graduate Theses, Dissertations, and Problem Reports. 4537.

https://researchrepository.wvu.edu/etd/4537

This Thesis is protected by copyright and/or related rights. It has been brought to you by the The Research Repository @ WVU with permission from the rights-holder(s). You are free to use this Thesis in any way that is permitted by the copyright and related rights legislation that applies to your use. For other uses you must obtain permission from the rights-holder(s) directly, unless additional rights are indicated by a Creative Commons license in the record and/ or on the work itself. This Thesis has been accepted for inclusion in WVU Graduate Theses, Dissertations, and Problem Reports collection by an authorized administrator of The Research Repository @ WVU. For more information, please contact researchrepository@mail.wvu.edu. 
Health Promotion during Midlife:

The Influence of Internal Health Locus of Control and Future Time Perspective

\author{
Sarah T. Stahl \\ Thesis submitted to the \\ Eberly College of Arts and Sciences \\ at West Virginia University \\ in partial fulfillment of the requirements \\ for the degree of \\ Master of Science \\ in \\ Psychology \\ Julie Hicks Patrick, Ph.D., Chair \\ JoNell Strough, Ph.D. \\ Kevin Larkin, Ph.D. \\ Department of Psychology \\ Morgantown, West Virginia \\ 2009
}

Keywords: midlife, health promotion, internal health locus of control, future time perspective 


\begin{abstract}
Health Promotion during Midlife:

The Influence of Internal Health Locus of Control and Future Time Perspective
\end{abstract}

Sarah T. Stahl

Health promoting behaviors are typically categorized as behaviors that move individuals towards optimal health while concurrently decreasing one's susceptibility to disease and illness (Becker \& Arnold, 2004; Breslow, 1999). When compared to other developmental age periods, less is known about health promotion in midlife (Merrill \& Verbrugge, 1999). Thus, the present study examined the relations among demographic variables, future time perspective, internal health locus of control, and middle-aged adults' engagement in health promotion. Data from 109 middle-aged adults between the ages of 40 and 66 were collected via an online survey. Results indicated that the data fit the model poorly $\left.\chi^{2}(\mathrm{df}=6 ; \mathrm{N}=109)=13.791 \mathrm{p}<.05\right)$, CFI $=.867$, $\mathrm{TLI}=.667, \mathrm{RMSEA}=.110$. Despite the poor fit, the path model accounted for a substantial amount of variance in health promotion $\left(R^{2}=.30\right)$. The model indicated that future time perspective and internal health locus of control were associated with engagement in health promotion. In addition, both age and adults' perceptions of the severity of their chronic health conditions were associated with future time perspective. Findings from this study may help inform the design of health interventions. Specifically, results suggest that interventions should consider integrating future time perspective into a theoretical framework in understanding why middle-aged adults choose to engage in health promotion. 


\section{TABLE OF CONTENTS}

TITLE PAGE .

ABSTRACT .

LIST OF TABLES

LIST OF FIGURES

LIST OF APPENDICES

INTRODUCTION

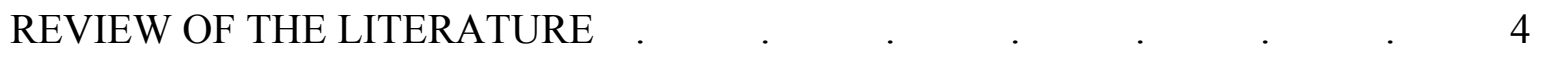

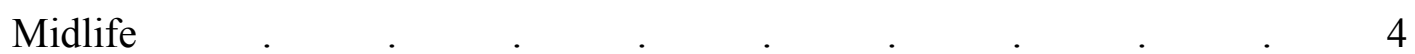

Emergence of Midlife as a Separate Age Period $\quad . \quad$. $\quad$. 4

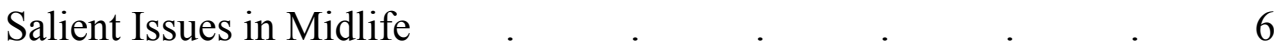

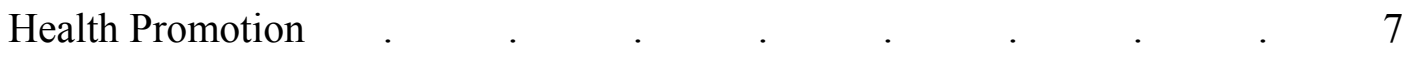

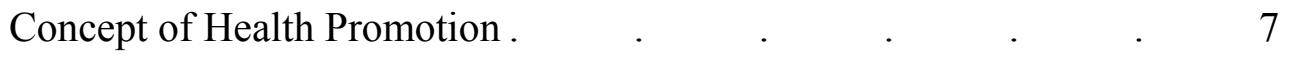

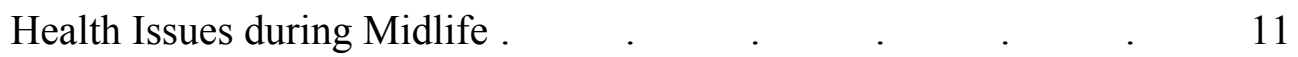

Psychological Influences on Health Promotion $\quad . \quad$. $\quad . \quad$. 12

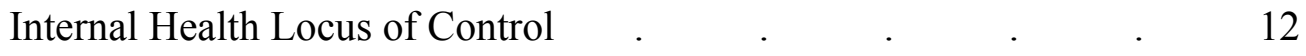

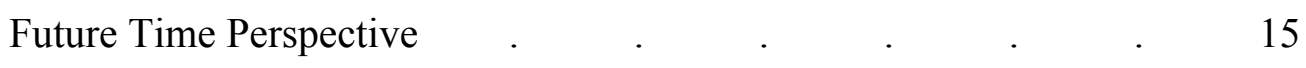

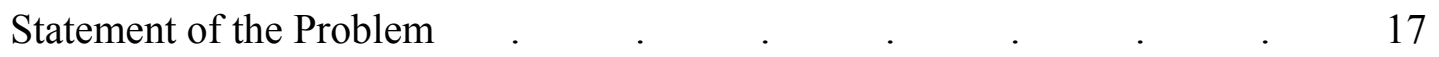

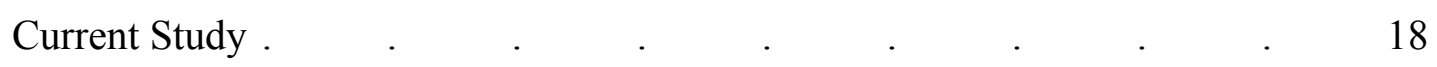

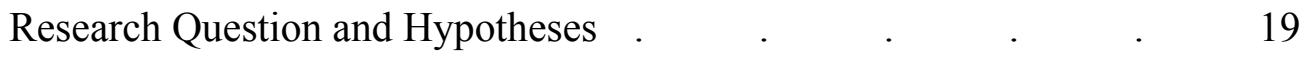

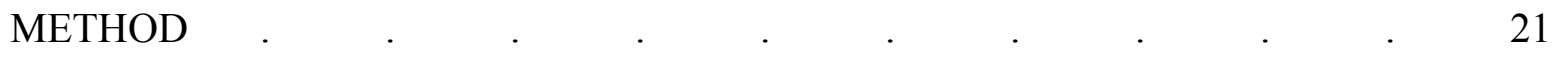

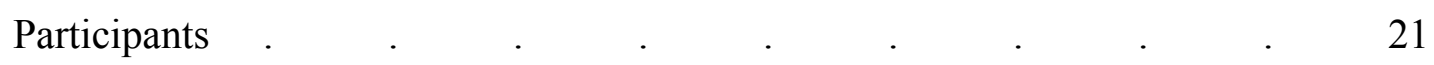

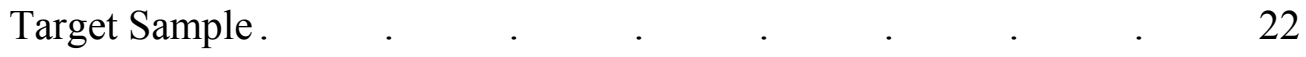




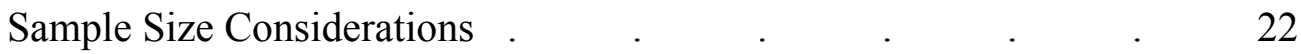

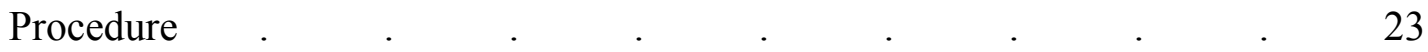

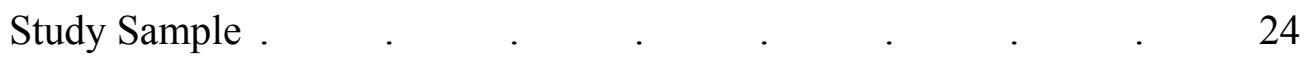

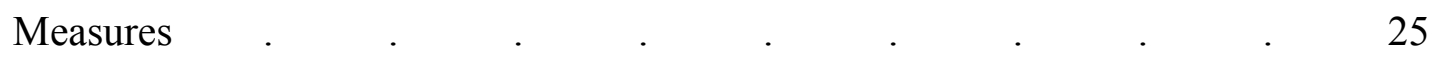

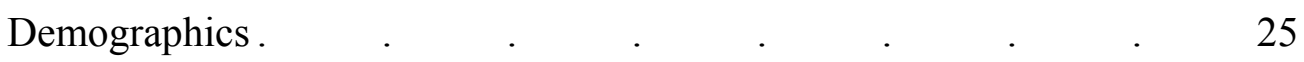

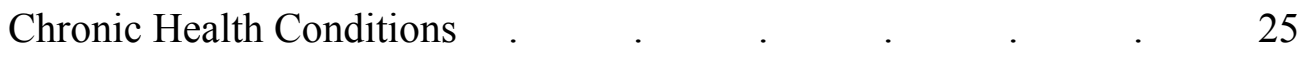

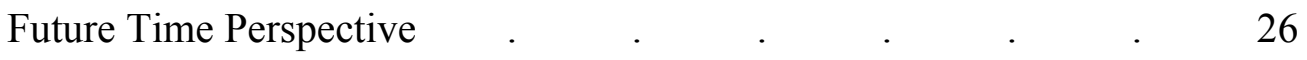

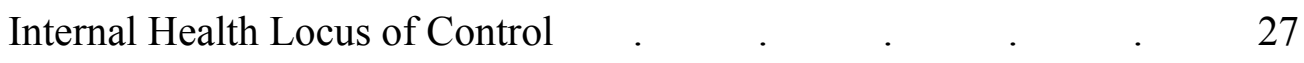

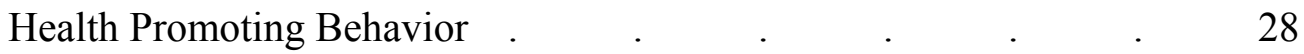

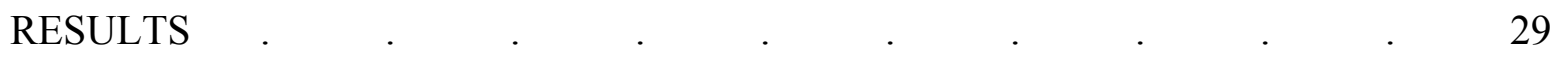

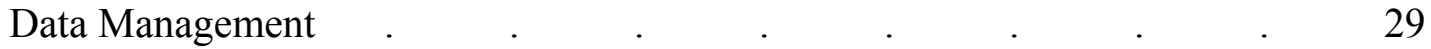

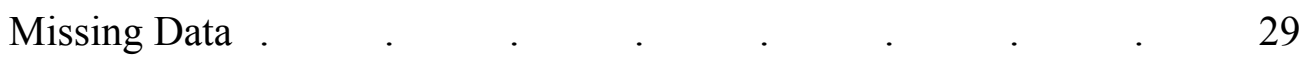

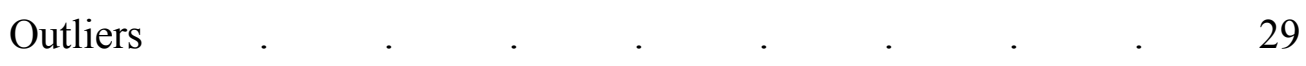

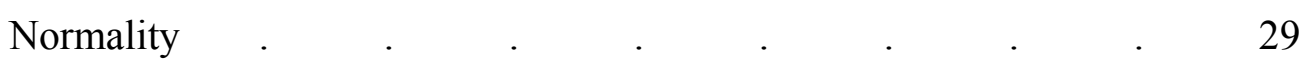

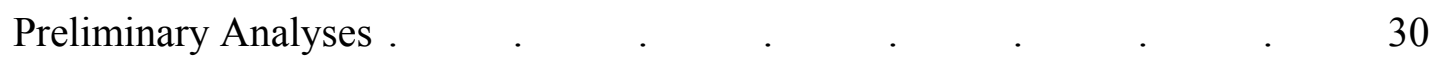

Descriptive Information $\quad . \quad$. $\quad . \quad$. $\quad . \quad$. 30

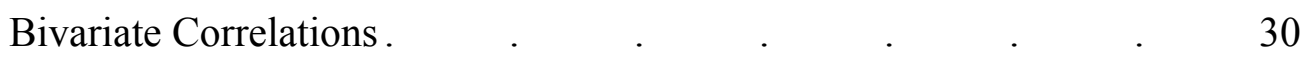

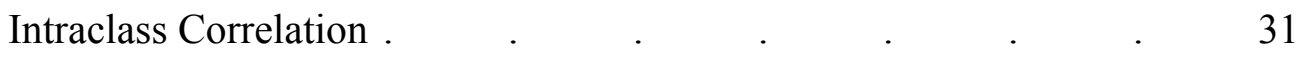

Analytical Approach: Path Analysis . $\quad . \quad$. $\quad . \quad$. $\quad . \quad 31$

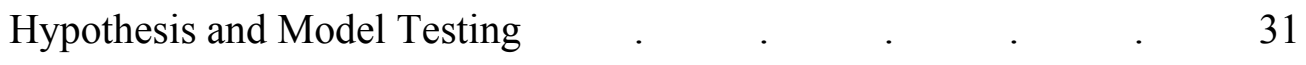

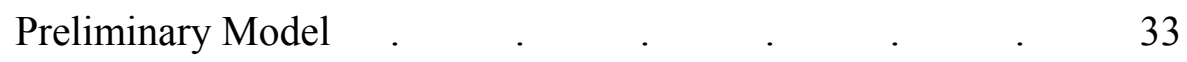

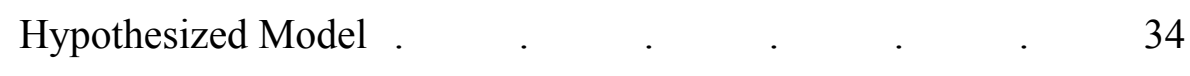

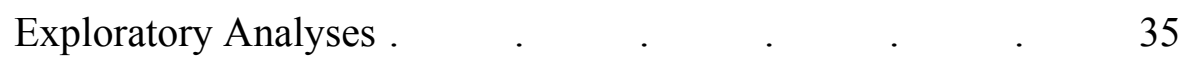


Health Promotion Domains . $\quad . \quad$. $\quad$. 35

$\begin{array}{lllllllll}\text { Multiple Regression } \quad . \quad & \text {. } \quad ~ & \text {. } & 37\end{array}$

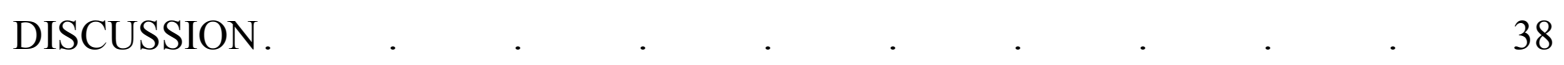

Review of Research Objectives $\quad . \quad$. $\quad$. $\quad$. $\quad$. $\quad$. $\quad 38$

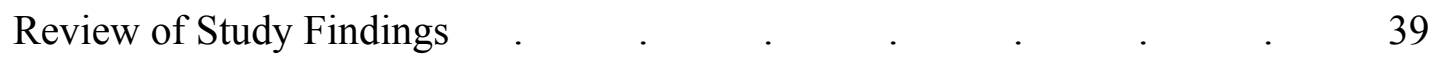

Overall Fit of the Model $\quad . \quad$. $\quad$. $\quad$. $\quad$. $\quad$. $\quad 39$

Influence of Age on Health Promotion $\quad . \quad$. $\quad$. $\quad$. 40

Influence of Age on Future Time Perspective . $\quad$. $\quad$. $\quad$. 41

Influence of Age on Internal Health Locus of Control $\quad$ $\quad$ $\quad 42$

Influence of Gender on Health Promotion $\quad$. $\quad$. $\quad$. $\quad$. 42

Influence of Gender on Internal Health Locus of Control . 43

Influence of Perceived Functional Limitation on

Future Time Perspective $\quad . \quad$. $\quad$. $\quad$. $\quad$. $\quad$. 44

Influence of Perceived Functional Limitation on
Internal Health Locus of Control . . .

Influence of Future Time Perspective on

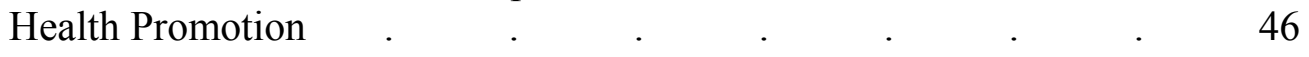

Influence of Internal Health Locus of Control on
Health Promotion

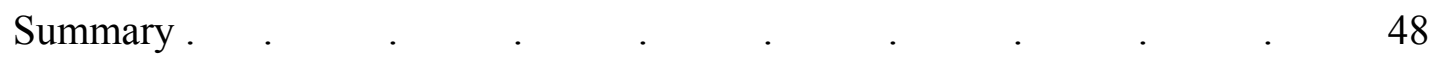

Domains of Health Promotion $\quad . \quad$. $\quad$. $\quad$. $\quad$. 50

Limitations and Future Directions $\quad . \quad$. $\quad . \quad$. $\quad$. $\quad$. 51

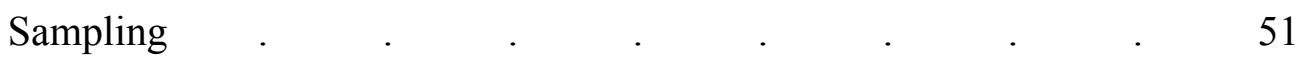

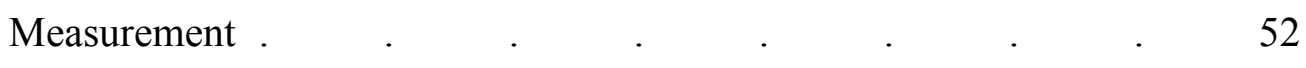

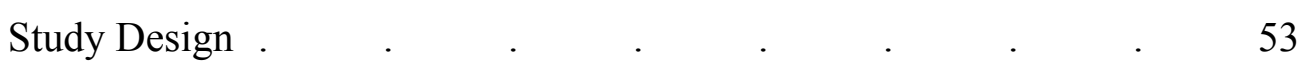




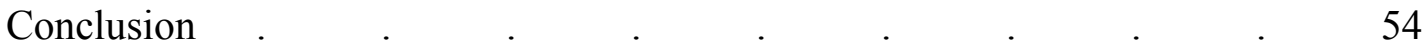

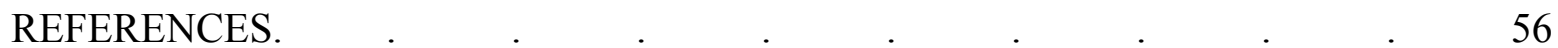




\section{LIST OF TABLES}

1. Descriptive Statistics for Demographic Variables . . . . . . 64

2. Means and Standard Deviations for Key Study Variables _ . . . . 67

3. Bivariate Correlations among Key Study Variables . _ . . . $\quad 68$

4. Standardized and Unstandardized Estimates for Preliminary

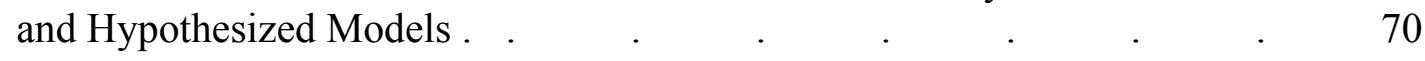

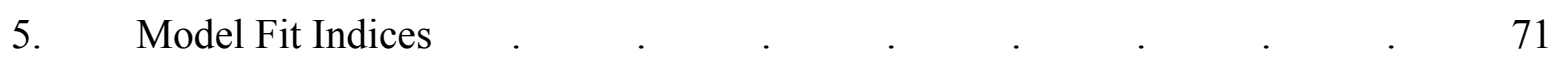

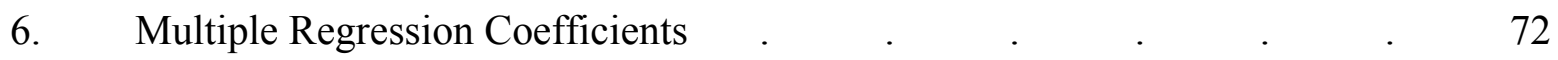




\section{LIST OF FIGURES}

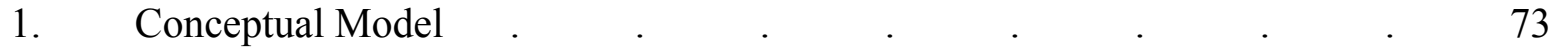

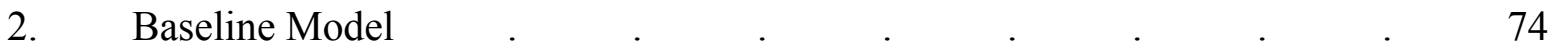

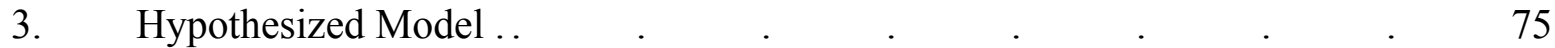


LIST OF APPENDICES

APPENDIX A: Personal Data Form . . . . . . . . . 76

APPENDIX B: Health Conditions Checklist . $\quad$. $\quad$. $\quad$. $\quad$. $\quad 80$

APPENDIX C: Future Time Perspective $\quad . \quad$. $\quad$. $\quad$. $\quad$. $\quad$. 81

APPENDIX D: Multidimensional Health Locus of Control Scale: Form A . $\quad$. $\quad 82$

APPEXDIX E: Health Promotion Lifestyle Profile II $\quad . \quad$. $\quad$. $\quad$. 83 


\section{Introduction}

Relative to other age periods, limited research exists on midlife (Brim, Ryff, \& Kessler, 2004). One explanation for this is that despite the popular conception of a midlife crisis, which has been difficult to validate empirically (Rosenberg, Rosenberg, \& Farrell, 1999), midlife has been viewed as a calm, stable age period, where little development took place (Skaff, 2006). In Erikson's theory on psychosocial development (Erikson, 1982) he described midlife as a time when individuals are concerned with future generations and are thus occupied with responsibilities tied to work, family, and community roles. In addition to Erikson, researchers have recently suggested that there is wide variability during the course of midlife because the experiences of middle-aged adults are so diverse due to the range of social roles that middle-aged adults are balancing (e.g., spouse, parent, coworker, caregiver, community member, etc.) (Lachman, 2004).

In addition to balancing social roles (e.g., spouse, parent), midlife is a time when adults may begin to experience declines in their physical health (e.g., hearing, vision problems). Researchers suggest that middle-aged adults can draw upon the experiences and knowledge they have gained thus far to maintain and improve their physical and psychological well-being into late life (Lachman, 2004). Thus, research is needed to understand how middle-aged adults compensate for age-related losses that emerge during midlife. There is growing interest in optimizing the aging process (Lachman, 2004); therefore, focusing on midlife development would be crucial to delay or minimize biological, social, and psychological changes that occur with old age (Moen \& Wethington, 1999).

In the health domain, studies generally report that older adults tend to engage in more health promoting behaviors than younger adults (Becker \& Arnold, 2004; Zanjani Schaie, \& 
Willis, 2006). Health promoting behaviors (e.g., exercise, dietary management) are defined as behaviors that may increase longevity while concurrently decreasing one's susceptibility to disease (Becker \& Arnold, 2004). Researchers caution that engagement in health promotion can not be generalized to all health behavior domains (Zanjani et al., 2006). For example, although older adults may be engaging in more dietary changes than middle-aged adults (see Becker \& Arnold, 2004), it is uncertain whether middle-aged adults are choosing other health promoting behaviors (e.g., physical activity).

Furthermore, although equivocal, additional research indicates that engagement in health promotion may be related not only to age but to health status, as well. For example, having a chronic health condition in midlife may increase the likelihood that middle-aged adults engage in health promoting behaviors because being diagnosed with a disabling condition may motivate adults to change their current health habits (Zanjani et al., 2006). Other research (Traywick \& Schoenberg, 2008), however, suggests that having a chronic health condition, specifically coronary heart disease, may decrease the likelihood that women participate in health promotion because their compromised health status may decrease their exercise self-efficacy, which limits participation in health promotion, specifically physical activity. Thus, it is important to disentangle the influence of chronic health conditions in health promoting behavior.

Engagement in health promotion may also be influenced by specific psychological constructs. For example, numerous studies suggest that a strong sense of internal health locus of control is related to better overall health, greater frequency of health promoting behaviors, and decreases in functional limitations (Ziff, Conrad, \& Lachman, 1995). Internal health locus of control is defined as having a perceived sense of personal power over the outcomes of one's health (e.g., having feelings that one can control their own health destiny) (Lachman \& Firth, 
2004; Wallston, Wallston, \& DeVellis, 1978). However, it is unclear which specific types of health behaviors (e.g., caloric restrictions, exercise, stress management techniques) are influenced. Additionally, Skaff (2006) reported a dynamic relationship between individuals' control beliefs and environment. However, there is little empirical research that investigates whether life events, such as a chronic health condition diagnosis during midlife, influences internal health locus of control. Because those with a greater sense of internal control are more likely to take action when it comes to their health treatment (e.g., seeking help after a medical diagnosis) (Lachman \& Weaver, 1998b), research should explore whether control beliefs are related to participation in health promoting behaviors.

Lastly, socioemotional selectivity theory (SST, Carstensen, Isaacowitz, Charles, 1999) asserts that individuals prioritize goals depending on the amount of time he or she perceives is left to live (i.e., future time perspective, FTP). A scarcity of FTP research exists in the health domain (Löckenhoff, \& Carstensen, 2007); however, FTP may relate to engagement in health promotion. According to SST, when future time is perceived as limited, adults set emotionally meaningful goals in order to achieve short-term benefits. In contrast, when future time is perceived as unlimited, adults set goals to optimize the future (Lang \& Carstensen, 2002). Few researchers have investigated whether having an expansive, unlimited FTP influences engagement in health promoting behaviors (e.g., exercise) because adults are focusing on goals that optimize their future (e.g., increase longevity). Moreover, a majority of work examining FTP compares older adults to younger adults; as a result, it is unclear how midlife influences adults' future time perspective, especially for comorbid older middle-aged adults, who may be preparing for the transition into old age (Cate \& John, 2007). 
Despite efforts to increase health promoting behaviors in adults (e.g., increased promotion of the My Pyramid food guide, Healthy People 2010 objectives) an estimated 60\% of adults are not physically active, only $25 \%$ consume the recommended daily servings of fruits and vegetables (Centers for Disease Control, 2001), and more than one third of adults are considered obese (US Department of Health and Human Services, 2007). Because poor nutrition and an inactive lifestyle are associated with poor health and increased risk for obesity, a more thorough understanding of the demographic and psychological influences of engaging in health promotion is important so that future health intervention programs can maximize the likelihood of success. The current study examined the personal and psychological correlates of health promotion in a sample of community-dwelling middle-aged adults.

\section{Review of the Literature}

The following review of the literature is divided into six sections. The first section describes the age period of midlife. The second section summarizes the area of health promotion. The third section describes how internal health locus of control influences health promotion. The fourth section summarizes how future time perspective may influence health promotion. The final section outlines the current study's research question and hypotheses.

\section{Midlife}

\section{Emergence of Midlife as a Separate Age Period}

The U.S. Census Bureau (2005) reports that there are 82.7 million middle-aged adults between the ages of 40 and 60, (28 percent of the population), currently residing in the United States. Moreover, this age group is one of the fastest growing, and within the last five years, the population estimate in this age group increased by ten million. However, this boost is not surprising because it is reflective of the Baby Boom cohort (b. 1946-1962) moving through 
middle-age (U.S. Census Bureau, 2005). The entrance of the largest cohort in history (baby boomers) into midlife has created a large demand for information regarding psychological and social development that occurs during this stage of life. Midlife research has often been neglected by researchers and, until recently, was described in two conflicting manners; as either a calm, stable phase on the way to old age (Moen \& Wethington, 1999) or as a hectic time of crisis (which has later been debunked) (Wethington, 2000).

A majority of midlife research was generated from the Midlife in the United States (MIDUS) National Survey. MIDUS defines the age period from 40-60 years as reflective of midlife (Brim, et al., 2004). However, Lachman (2004) states that it is not uncommon for researchers to add a ten year range on either end, especially the upper limit, because Americans are living longer and remaining healthier. In addition, with an expanding period of midlife, researchers may find it useful to compare young middle-aged adults to older middle-aged adults because the experiences and social roles (e.g., spouse, caregiver) of a 40-year-old entering middle adulthood may be markedly different than the experiences and social roles (e.g., widow, grandparent) of a 60-year-old leaving middle adulthood and entering old age (Lachman) due to age and cohort differences. Such a wide midlife age range (20 to 40 years) may obscure important within group differences.

One suggestion as to why the study of midlife development has emerged is due to the western cultural ideal to remain youthful and vibrant (Lachman, 2004; Saucier, 2004). A majority of baby boomers (who are considered the first large group of affluent and knowledgeable adults to pass through midlife), are interested in the ways in which they can optimize the aging process; accordingly, this cohort may have a marked interest in health promotion because of the need to maintain and prevent future physical problems (Lachman). 
Midlife health is often an indicator of old age morbidity (Grzywacz, 2007) and thus, midlife provides a window of opportunity for adults to recognize and change the course of their own psychological and physical aging.

\section{Salient Issues in Midlife}

There is evidence to suggest that middle adulthood is characterized by both positive and negative aspects. For example, Lachman (2004) found that middle-aged adults frequently complained about not having enough time to get everything done, their memory, and changes in the physical health, including concerns about chronic illnesses. In contrast, the adults noted that the best aspects of midlife were the wealth of experiences that they had gained thus far in life and, having a sense of freedom, independence, and personal control. This dynamic interplay of both gains and losses can be indicative of midlife if researchers view this age period from a lifespan perspective, where one's context and environment are influencing the diversity of midlife experiences (see Baltes, 1987).

Secondly, midlife is considered to be an age period when adults take on a variety of social roles and are expected to balance demands from multiple domains (Grzywacz, 2007). For example, midlife is often characterized as a time when adults are moving in and out of various roles and relationships, which forces them to alter components of their identity as they become spouses, divorcees, grandparents, caregivers, coworkers, volunteers, and retirees (Moen \& Wethington, 1999). Middle-aged adults' lives are often illustrated as an interrelation of numerous pathways such as schooling, marriage, occupation, parenthood, and caregiving (Moen \& Wethington). Because of the multitude of roles that middle-aged adults can pursue, there is great individual variability in social roles during this time. Further, it is possible that adults may display success in one domain (e.g., work) but may feel overwhelmed in another (e.g., family). 
Therefore, middle-aged adults can display an array of gains and losses with respect to the multiple domains of life (Lachman, 2004).

In sum, although there has been an increase in research, less is known about midlife than any other developmental period (e.g., infancy, childhood, adolescence, older adulthood) (Lachman, 2004; Miller \& Lachman, 2000). Midlife is a time when chronic illnesses or diseases (e.g., high blood pressure, arthritis) that threaten middle-aged adults' sense of health and wellbeing begin to emerge. Such physical ailments signal stress because they represent the aging process, which is typically viewed negatively in Western cultures (Saucier, 2004). However, midlife is a time when adults can draw on the experiences they have gained from various roles and are aware of the opportunities that exist to enhance their future quality of life. It is also a time when a sense of control can motivate adults to improve declines in physical and cognitive functioning (Lachman, 2004).

\section{Health Promotion}

\section{Concept of Health Promotion}

Research on health behaviors has begun to switch focus from disease prevention to the concept of health promotion. Disease prevention signifies environmental and personal attempts to decrease the prevalence rates of cancers and other diseases. However, health promotion is not synonymous to being disease free; it is a term that signifies altering one's behavior (e.g., adopting physical activity) to maximize health potential (e.g., improved cardiovascular fitness) while concurrently enhancing capacity for living (e.g., decreased functional disability) (Breslow, 1999; Grzywacz \& Keyes, 2004). This switch from an interest in disease prevention to health promotion is primarily due to individual's increasing life expectancies, which may be a result of the decreased threat of disease (e.g., smallpox, measles) (Breslow). Although health promotion 
should not be confused with disease prevention, the two concepts are intertwined because engaging in health promotion practices can prevent certain chronic illnesses such as coronary heart disease (Breslow). Interventions that focus on health promotion highlight the idea of achieving optimal health (Grzywacz \& Keyes, 2004) by implementing self-initiated actions that serve to enhance overall well-being. Additionally, the idea of a healthy lifestyle has been described as comprised of both health promotion and disease prevention components (Walker, Sechrist, \& Pender, 1988). Health behaviors, both risky (e.g., smoking) and promotive (e.g., exercise) are highly predictive of illness, disability, and mortality rates (Grzywacz \& Keyes). Leventhal and colleagues (2001) suggest that engagement in health promoting behaviors (e.g., physical activity) may minimize the negative effects of physical (e.g., decrease in muscle strength) and psychological (e.g., cognitive decline) changes that result from normative aging. More specifically, engagement in physical activity is considered a key component in maintaining cognitive health and decreasing the onset of age-related cognitive declines. A meta-analysis, conducted by Colcombe and Kramer (2003), of physical activity interventions from 1996 to 2001 indicated that aerobic exercise training significantly enhanced cognitive functioning, particularly executive functioning, of sedentary older adults.

Callaghan (2005) identified two major factors that lead to an increasing probability for adults to engage in health promoting behaviors. An adequate income and having health insurance was associated with increased frequency of healthy promotion and exercise self-efficacy (e.g., perceived ability in performing physical activity). In general, social support, being married, and having few or no children was predictive of an increased frequency of health promoting behaviors. Those with a chronic condition or disability also reported practicing more healthy behaviors than those without a chronic health condition (Callaghan). With respect to gender, 
there is an abundance of research to suggest that men are more likely to engage in regular physical activity when compared to women (e.g., Hageman, Walker, Pullen, Boeckner, \& Oberdorfer, 2005; Rimer, McBride, Crump, 2001; Seger, Spruijt-Metz, \& Nolen-Hoeksema, 2006). However, women are more likely to talk to their primary care physicians and seek medical help when compared to men, thus indicating that women may be more likely to engage in a wide variety of health promoting behaviors (George, 2001).

Research is mixed with respect to identifying the frequency of health promoting behaviors across age groups. Results appear to depend on the health promotion domain of interest. For example, in the physical activity domain, a plethora of research (see Nelson, Rejeski, Blair, Duncan, Judge, King et al., 2007; Prohaska et al., 2006,) suggests that engagement in regular physical activity decreases with age and older adults are more likely to be sedentary when compared to middle-aged and younger adults. Because fewer than one third of older adults participate in regular exercise, physical inactivity in late-life is considered to be a major public health threat because of the increased medical costs and health outcomes (e.g., diabetes) that are associated with such a lifestyle (Prohaska et al.).

Some research (George, 2001; Leventhal, Rabin, Leventhal, \& Burns, 2001; Walker, Volkan, Sechrist, \& Pender, 1988; Zanjani, et al., 2006) suggests that older adults are more likely to engage in health promoting behaviors than middle-aged adults because death and morbidity are salient issues for older adults; which are motivators for behavior change and engagement in health promotion. Furthermore, research by Zanjani amd colleagues indicated that health behavior change varies by health domain (e.g., food consumption, seeking medical care) and adults' health status (e.g., cardiovascular disease status versus condition free status). Particularly, adults who were diagnosed with cardiovascular disease were more likely to engage in three 
specific health promotion domains (e.g., food preparation, food consumption, and medical care) than adults with a condition free status (Zanjani et al.). These adults' health behavior change may represent their awareness of health promotion strategies as means to reduce the risk of future illness (caused by the either the aging process or co-morbidity) or premature mortality. Thus, health behavior change and engagement in health promotion may be related not necessarily to an individual's age but their current health status.

In a second study, Becker and Arnold (2004) examined whether older adults were more likely to engage in a variety of health promoting behaviors when compared to middle-aged adults. The authors defined health promoting behaviors as behaviors that were intended to maintain or enhance physical functioning (e.g., cardiovascular performance) and psychological functioning (e.g., perceived well-being and happiness). Results indicated that older adults were only more likely to engage in health responsibility (e.g., medical checkups) and nutrition (e.g., balanced diet) behaviors than middle-aged adults. When compared to older adults, middle-aged adults were more likely to engage in stress management behaviors (e.g., relaxation techniques). This suggests that there may be differences in the types of health promoting behaviors in which middle-aged adults choose to engage (Becker \& Arnold). The authors note the importance of continuing to conduct research regarding why certain age groups may only choose to engage in particular types of health behaviors (e.g., nutrition, physical activity) because this may challenge the prevailing idea that older adults are more readily able to adopt health promoting behaviors than their middle-aged counterparts.

Research on gender differences in health promotion assert that females are more likely than males to engage in a wider variety of health promoting behaviors (Callaghan, 2005; George ,2001). One explanation is that women are more likely to report their physical and 
emotional symptoms to health care professions, are more likely to seek health care, and are more willing to talk to their physicians regarding their health status. Although there is a profusion of research to suggest that women engage in less physical activity when compared to males (e.g., Hageman, et al., 2005; Rimer, et al., 2001; Seger, et al., 2006), some researchers assert that women may be more likely to care for their bodies in other ways (e.g., nutrition, seek health screens) because of the western beauty cultural ideal to remain vibrant and young. This Western cultural ideal signifies norms for women's appearance, specifically that "looking old" is undesirable, thus influencing women to be more aware of their aging bodies (Gosselink, Cox, McClure, \& DeJong, 2008; Saucier, 2004).

Health Issues during Midlife

Midlife is often a time when physical changes begin to surface (Merrill \& Verbrugge, 1999). Adults' health habits and lifestyle choices (along with genetics) have a significant influence on the emergence of such physical changes (e.g., increase weight gain) and the ability to cope with these changes. Midlife is a time when numerous physiologic changes are surfacing. For example, the heart starts losing its effectiveness to pump and the body's basal metabolic rate gradually declines (Katchadourian, 1987). In addition, sensory changes are becoming noticeable. Middle-aged adults' senses of smell and taste begin to diminish. Gradual hearing loss begins and the eye's ability to accommodate continues to decline (Horvath \& Davis, 1990). Furthermore, sleep patterns become more disruptive, as more frequent wakings occur throughout the night. Although the prevalence of physical decline begins in midlife, there are also positive health changes that are occurring. For example, there is a decrease in accidents and the susceptibility to colds and allergies starts to decline (Merrill \& Verbrugge). 
Even though most of the conditions that arise in midlife are nonfatal, the number of chronic conditions that do arise continue to increase with each decade (Merrill \& Verbrugge, 1999). Further, within our culture's obesogenic environment, researchers propose that the number and severity of chronic illnesses (e.g., heart disease) may continue to increase at an alarming rate (Kumanyika, Jeffery, Morabia, Rittenbaugh, \& Antipatis, 2002; Sinburn, Gill, \& Kumanyika, 2005). Men have a higher incidence of fatal diseases (e.g., coronary heart disease, stroke) while women have a higher prevalence of nonfatal diseases (e.g., arthritis, varicose veins) (Merrill \& Verbrugge; Verbrugge, 1985). The risk of acquiring a disease highly depends not only on genetic predisposition but one's engagement in health-promoting behaviors. Delaying or preventing a chronic condition or physiologic decline depends to a large extent on the manner in which middle-aged adults live their lives (e.g., whether they choose to engage in physical activity) and care for themselves (e.g., blood pressure screenings) (Merrill \& Verbrugge; Wister $\&$ Romeder, 2002). Some researchers suspect that because of the increased prevalence in chronic illnesses, middle-aged adults may be spending more time dealing with these conditions (e.g., disease treatment) than focusing on health promoting practices and ways to increase longevity (Lachman, 2004). However, other research (see Zanjani et al.) asserts that being diagnosed with a chronic health condition may motivate individuals to change their current lifestyle and engage in more health promotion. For example, Blanchard and colleagues (2003) found that about half of adult cancer survivors quit smoking and made a change to their dietary behavior after their cancer diagnosis.

\section{Psychological Influences on Health Promotion}

Internal Health Locus of Control 
Internal control beliefs are defined as one's belief that outcomes (e.g., health status) are due to internal, dispositional forces (e.g., self-efficacy) and less so due to external sources (e.g., chance, physicians) (Skaff, 2007, Wallston, Wallston, \& DeVellis, 1978). In other words, individuals with high internal locus of control believe that their behaviors can bring about a desired outcome (Lachman \& Firth, 2004). Control beliefs influence the way in which individuals deal with stressful events (e.g., diagnosis of a chronic disease) (Rodin, 1986);

Midlife may be indicative of peak internal control and self-efficacy because, when compared to other age periods, midlife is characterized by an increase in leadership roles (e.g., spouse, parent) and responsibilities (e.g., work, family duties) (Clark-Plaskie \& Lachman, 1999). Longitudinal research on global control beliefs (e.g., control beliefs collapsed across domain) indicates that midlife is characterized by high levels of internal control, followed by chance factors and beliefs in powerful others. This pattern is reversed in older adults where beliefs in powerful others is the greatest, followed by chance factors and internal control (Clark-Plaskie \& Lachman).

Conversely, within life-span developmental theory (see Baltes, 1987), because of the gains (e.g., increased confidence in work domain), and losses (e.g., decreased physical ability in health domain), that middle-aged adults experience; there are shifts in control beliefs within each of these domains (Skaff, 2006). Thus, global control measures may not be particularly useful. What many researchers conclude (Clark-Plaskie \& Lachman, 1999; Lachman \& Firth, 2004; Skaff, 2006,) is that some domains, specifically health, work, and family, are more valued in midlife than are others. Therefore middle-aged adults' sense of internal control has been hypothesized to vary by domain. For example, the work domain is especially important in 
midlife; therefore middle-aged adults often perceive a greater sense of control in this domain when compared to younger and older adults (Lachman \& Firth).

Although middle-aged adults typically report internal control beliefs for the health domain (Clark-Plaskie \& Lachman, 1999), researchers warn that the health domain may be more of a challenge to control because of the inevitable changes that occur with aging (Skaff, 2006). Lachman and Weaver (1998) assert that although previous research on control beliefs indicated that adult's internal control beliefs continuously decreased with age, their research found no age differences (middle-aged adults versus younger and older adults) in the health domain, which may be indicative of widespread attention in the media to take control of one's health in order to optimize aging.

Research suggests a strong link between sense of control and well-being (Skaff, 2007). A greater sense of internal locus of control is often associated with better adjustment to chronic disease diagnosis (Skaff, 2007), better self-rated health, less severe physical limitations (Lachman, 2004), fewer acute and chronic illnesses (Lachman \& Weaver, 1998b), and imperative for successful aging (Lachman \& Weaver) because adults are better equipped to adjust to the aging process (Lachman \& Firth, 2004). Additionally, those with a higher internal sense of control over their health reported better access to medical care and believed there were many things they could do to stay healthy (Lahman \& Weaver, 1998a). Likewise, those with a greater sense of internal control are more likely to engage in health-promoting behaviors because they feel that taking action will make a difference in their health. Results from the MIDUS study (Lachman \& Firth) suggest that greater internal control beliefs were related to decreases in hipwaist ratios because adults' engaged in more health promoting behaviors (e.g., dietary management and exercise). Moreover, research suggests that individuals with a greater sense of 
internal control may return to homeostasis faster after a stressful event (because of lower levels of cortisol) and have immune systems that are better able to fight disease (Lachman \& Weaver, 1998b).

Numerous studies are in accord with the idea that a strong sense of control is related to better health outcomes, health promotion, and higher self-ratings of health. Internal health locus of control has been linked to engagement in a number of health promoting behaviors such as information seeking from health professionals, exercising, seat belt use, taking vitamin supplements, more frequent medical checkups, and limiting red meat intake (Ziff et al., 1995). Because midlife is a time when adults begin to notice physiologic changes and declines, of interest is how internal locus of control explains middle-aged adults' ability to deal with these stressors that characteristically accompany the aging process.

\section{Future Time Perspective}

Socioemotional selectivity theory (SST; Carstensen, 1993) proposes that individuals select specific goals depending on the perceptions of their future time to live as being either open ended or limited (e.g., future time perspective, FTP; Lang \& Carstensen, 2002). When future time is perceived as open ended, goals that focus on optimizing the future are prioritized. Examples of such goals include information seeking and selecting contacts that could be useful in the distant future. However, when future time is perceived as limited, emotionally meaningful goals are selected, because the individuals are concerned with achieving short term benefits (Lang \& Carstensen).

Although there is a paucity of health behavior research that investigates future time perspective as a potential mediator; future time perspective may be a useful construct in understanding why middle-aged adults choose to engage in health promotion. In other words, 
because individual's behaviors are influenced by their personal goals (Löckenhoff $\&$ Carstensen, 2007), middle-aged adults may choose to engage in health promotion if it is in accord with their goal content (e.g., goal to optimize future or goal to receive short term benefits). In the health domain, adults who view time as open ended (e.g., selecting goals to optimize the future) may engage in activities that involve gathering information about health behaviors and executing a dietary and physical activity routine. On the contrary, individuals who see their future time as unlimited are more likely to not only prevent negative outcomes (e.g., chronic illness) but promote positive outcomes (e.g., emotional and physical well-being). For example, adults who are future oriented may be more motivated to maintain an exercise regimen and seek out preventative measures (e.g., screening tests) than those who are not future oriented (Löckenhoff $\&$ Carstensen, 2004). In contrast, adults who view their future time as limited (e.g., selecting immediate short-term goals) may try to immediately alleviate harmful symptoms (i.e., take over the counter medication instead of consulting a physician), avoid negative information, and promote emotional well-being (Löckenhoff \& Carstensen, 2007).

Age differences in FTP suggest that young adults focus on future opportunities and older adults focus more on maximizing current positive experiences past (i.e., time is limited) indicating that FTP may become limited with age. Additionally, as people move from young adulthood to old age, priorities shift from meeting information seeking goals to emotionally meaningful goals (Lang \& Carstensen, 2002). However, how FTP is depicted at middle adulthood has not been studied extensively, signifying further research in this developmental area. For example, research by Fredrickson and Carstensen (1998) suggest that future time perspective may be influenced more by health status than by chronological age. More specifically, they found that a sample of HIV-positive men had limited future time perspectives, 
regardless of age, because they viewed their remaining time to live as limited. Cate and John (2007) note that it is important for future research to investigate how FTP changes as middleaged adults move into old age and adapt to the negative consequences that are associated with the aging process, including the emergence of physical changes and declines.

When time is perceived as unlimited, individuals foresee many opportunities and engage in activities that extend into the distant future. This may be imperative during midlife, when adults are attempting to achieve goals in a variety of domains (e.g., family, work, health) (Cate \& John, 2007). More specifically, midlife is a time when certain aspects of the self, such as confidence, leadership and responsibilities may increasing (Lachman, 2004), while at the same time, physical declines start to emerge (Merrill \& Verbrugge, 1999), reminding middle-aged adults of the aging process (Cate \& John). If midlife is a time of both psychological growth and physical decline, then both perspectives of future time may coexist during this period.

Furthermore, midlife may be divided into young-midlife, where opportunities are prioritized and adults feel as if there is ample amount of time left; and late-midlife, where losses are prioritized because of the realization that they are getting older and entering old age (Cate \& John).

\section{Statement of the Problem}

Despite efforts to increase awareness among aging adults regarding the importance of engaging in health promoting behaviors (particularly physical activity), participation in such behaviors remains low (Prohaska, Belansky, Belza, Buchner, Marshall, McTigue, et al., 2006). Thus, identifying strong predictors of health promotion is critical, especially in terms of developing future health interventions. Although the components of the tested model have been found to be related to health behaviors in previous research, most studies have not tested their relation simultaneously. Notably absent in the literature is the attention to the way in which 
future time perspective relates to engagement health promotion, specifically in midlife. Future time perspective may be an important construct for practitioners to consider when they are trying to understand how to increase adults' engagement in health promoting behaviors.

Furthermore, the prevalence rates for many chronic health conditions continue to increase with age (Piazza, Charles, \& Almeida, 2007); it is estimated that more than 49 million adults are living with some type of chronic condition (e.g., arthritis, heart disease) (Stuifbergen, 2006), and 36 million experience daily limitations due to one or more conditions (Adams, Lucas, \& Barnes, 2008). The current western obesogenic environment (see Swinburn, Egger, \& Raza, 1999) may be attributable to the increasing prevalence rates of chronic diseases. As a result, it is important to explore how middle-aged adults' perceived functional impairment, that is a result of their chronic health condition status, influences participation in health promotion. However, limited research has explored how perceived severity of dealing with such conditions interacts with psychological variables to influence participation in health promoting behaviors.

\section{Current Study}

The current study had two primary objectives. The first objective addressed the gap in the literature regarding midlife research as it relates to health promotion. More specifically, the first objective examined the relations among demographic variables (e.g., age, gender, and perceived impairment due to chronic health conditions), future time perspective, internal health locus of control, and engagement in health promoting behaviors.

The second objective addressed whether future time perspective and health locus of control would mediate the relations between the demographic variables (age, gender, and perceived impairment due to chronic health conditions) and engagement in health promotion. It was hypothesized that the effects of demographic variables on health promotion would be 
mediated by psychological processes (e.g., future time perspective, and internal health locus of control). In other words, it was expected that future time perspective and internal health locus of control would be the underlying mechanisms that explained the relation between the independent variables (e.g., demographic variables) and dependent variable (e.g., engagement in health promotion). Total mediation would be present if the effect of demographic variables on health promotion drops to zero when controlling for the two mediators.

Both objectives used a path analysis approach because it allowed for the examination of the overall fit of the data to the model, as well as the mediating role of future time perspective and health locus of control on middle-aged adults' health promoting behaviors.

\section{Research Questions and Hypotheses}

The following research question and hypotheses address the two primary objectives of the research. (The hypothesized set of relations can be seen in Figure 1).

RQ1. What influences middle-aged adults' engagement in health promoting behaviors?

H1. Age was expected to influence adults' participation in health promoting behaviors. Current research (see Prohaska et al., 2005 \& Nelson et al., 2007) suggests that the frequency of participation in physical activity, the most common type of health promotion, in lowest among older adults. Thus, younger middle-aged adults were expected to engage in more health promoting behaviors than older middle-aged adults.

H2: Age was expected to exert direct effects on future time perspective. Younger middle-aged adults would have a more open ended perspective than older middleaged adults who would have a limited perspective (Lang \& Carstensen, 2002). 
H3: Age was expected to directly influence individuals' health locus of control. Researchers (Lachman \& Firth, 2004; and Lachman \& Weaver, 1998) indicate that for health-related control, older adults generally had a lower sense of control over their health status than both middle-aged and younger adults. Therefore, older middle-aged adults were expected have a lower internal health locus of control than younger middle-aged adults.

H4. Callaghan (2005) and George (2001) state that women engage in health promotion more often than men and engage in a wider variety of practices (e.g., restricting daily activities, dietary changes, managing emotional stress); therefore, women were expected to engage in more health promoting behaviors than men.

H5. Gender was expected to exert direct effects on internal health locus of control. Results from the MIDUS study (Lachman \& Firth, 2004) indicate that men often report higher general control than women. Further, in the health domain, women were more likely to believe that their health was in the control of their doctor as compared to men. Thus, it was expected that men will have a greater sense of control over their health when compared to women.

H6. Middle-aged adults' perceived functional impairment due to their chronic health conditions was expected to directly influence future time perspective. Younger adults with HIV displayed similar goals as older adults, because both perceived their lives as approaching an end (Carstensen \& Fredrickson, 1998), thus it was expected that those adults who perceived experiencing more difficulty dealing with their chronic health conditions would view their future time as more limited 
than healthier adults (e.g. zero or fewer functional limitations) who would perceive their future as unlimited.

H7. Middle-aged adults' perceived functional impairment due to their chronic health conditions was expected to directly influence internal health locus of control. Lachman and Weaver (1998) indicate a negative association between the number of chronic conditions at midlife and control over one's health. Thus, middle-aged adults who viewed their functional impairment to be less severe were expected to have a greater internal health locus of control than middle-aged adults who perceived their functional impairment to be more severe.

H8. Future time perspective was expected to exert direct effects on engagement in health promoting behaviors; middle-aged adults with an unlimited perspective would focus on opportunities to optimize the aging process, and therefore engage in more health promoting behaviors, when compared to middle-aged adults with a limited future time perspective (Löckenhoff \& Carstensen, 2007).

H9. Internal health locus of control was expected to directly influence engagement in health promoting behaviors. Internal health locus of control over one's health status has been linked to engagement in a number of health behaviors such as medical checkups and exercising (Ziff, et al., 1995); therefore, middle-aged adults who have a greater sense of internal control over their health will engage in more health-promoting behaviors than middle aged adults who do not have a perceived sense of control.

Method

Participants 


\section{Target Sample}

Adults between the ages of 40 and 65 were recruited for the study. The age range was chosen for several reasons. First, current research on middle-aged adults (see Becker \& Arnold, 2004; Zanjani, et al., 2006) has included samples that lie within this age range. Second, the period of midlife is typically viewed as a social construction, where the starting and ending point depends on a specific life event (Lachman \& James, 1997). More specifically, most adults perceive midlife to start when one reaches their $40^{\text {th }}$ birthday and to end around age 65 years, when one typically retires from full-time employment (Moen \& Washington, 1999). Restricting the age range from 40-65 years allowed for the examination of health promotion in participants who were starting to experience the physical changes that accompany normative aging and are possibly coping with the onset of chronic diseases, but who are not at the point of experiencing functional or physical limitations.

\section{Sample Size Considerations}

Although there is disagreement in the literature pertaining to model sample size when using path analysis, Kline (2005) asserts that some researchers suggest an $N<200$ for small effects, an $N$ between 100-200 for medium effects, and an $N<100$ for large effects. However, model complexity must be considered when determining sample size and researchers suggest that a reasonable ratio of the number of cases to the number of parameters to be estimated should range from 5-10:1. (see Byrne, 2001; Kline, 2005). (Each causal path and construct is counted as a parameter in path analysis, (see Figure 1$)$ ). Further, a $\chi^{2}(\mathrm{df}=6)$ power analysis test was conducted using G Power 3.0. Results indicated that a sample size of 109 would provide sufficient power $(>.80)$ for a proposed model with 15 distinct parameters (see Figure 1) and a medium effect size $\left(\mathrm{R}^{2}=.30\right)$. 


\section{Procedure}

Data were collected during the Fall 2007 and Spring 2008 semesters at West Virginia University via an online data management system, SONA (e.g., http://wvu.sona-systems.com). Middle-aged adult participants were recruited by means of undergraduate referrals. Undergraduate students enrolled in psychology courses completed the online study (e.g., Health Promoting Behavior Study) and were asked if they thought their parents and/or grandparents would be interested in participating in the study as well. Undergraduates then referred their interested parents and grandparents for the current study by providing the primary investigator (PI) with contact information (e.g., full name, mailing address, and email address) of their middle-aged and older adult family members. Depending on which psychology course in which they were enrolled, undergraduate students who referred their parents and grandparents for the study were offered either course credit (e.g., homework credit) or extra credit.

The referred middle-aged adults received postcards in the mail describing the purposes of the current study and inviting them to participate in the online survey. The postcard also provided instructions for accessing the study online along with a username and password so they could log in to the SONA system and access the appropriate study (e.g., Health Promoting Behavior Study). Study participation was not timed and lab attendance was not required. Participation in the Health Promoting Behavior Study was contingent upon an online consent form. The online survey described the purposes of the study and allowed for participants to skip any question they did not want to answer. Additionally, participants were allowed to withdraw from the online study at any time. Participants who completed the online study were later mailed a postcard thanking them for their participation. 
Eight hundred forty-two participants were contacted to participate through referrals from undergraduate and graduate students at West Virginia University. One hundred sixty-seven adults responded to the recruitment ads that were mailed to them and completed the online study, a $20 \%$ return rate. The first part of the online study consisted of the consent form and the demographic questionnaire; part two of the online study consisted of questions that asked about the key study variables of interest. Of the 167, 58 individuals completed only part one of the study. In sum, the final sample consisted of 109 consenting participants. There were no significant demographic differences between the 109 participants and the 58 who did not complete part 2 .

Study Sample

The 109 middle-aged adults $($ men $=33$; women $=76)$ ranged from $40-66$ years $(M=$ $49.94, S D=4.96)$ and were primarily White $(94.5 \%)$; the remainder were African American (1.8\%), Asian American (.9\%) and Hispanic American (.9\%). A majority of participants (87\%) were residents of the Northeastern and Mid-Atlantic United States (e.g., West Virginia, Pennsylvania, Maryland, New Jersey, New York, Delaware, and Maine). Using the U.S. Department of Health and Human Service's body mass index categories, a majority of participants were overweight (40.4\%), and had a mean body mass index (BMI) of 28.04 (ranging from 19.39 - 43.04). The remainder were normal weight $(25.7 \%)$ and obese $(27.5 \%)$. Adults reported experiencing an average of 3.39 chronic health conditions. The most commonly reported health conditions were: difficulty dealing with headaches $(41.3 \%)$, arthritis (37.6\%), back problems (37.6\%), and high blood pressure (27.5\%). Half had a college degree (50.5\%) and $39.4 \%$ had a total annual family income of $\$ 100,000$ or greater. The remainder had a total income of $\$ 75,000$ - \$99,999 (23.9\%), \$50,000 - \$74,999 (15.6\%), \$25,000 - \$49,999 (13.8\%), 
and less than $\% 25,000(2.8 \%)$. Of the 109 participants, $80.7 \%$ were married, $11.9 \%$ were divorced, $4.6 \%$ were remarried after divorce, and $.9 \%$ was living with a partner. Demographic information for the final sample can be found in Table 1.

\section{Measures}

The online study included questionnaires that assessed demographics, chronic health conditions, future time perspective, internal health locus of control, and health promoting behaviors. In addition, items not related to the current study (e.g., positive and negative affect, disordered eating, and eating-related cognitions) were collected so that future associations between other health indexes (e.g., disordered eating) and health promotion could be investigated. Demographic Information

The demographic questionnaire collected data regarding participants' age, gender, marital status, education, and a variety of health information (e.g., height, weight, over-the-counter medication use, seat belt use, etc.) (see Appendix A).

\section{Chronic Health Conditions}

The Health Condition Checklist from the National Long-Term Care Survey (NLTCS, 1992) assessed the number and severity of chronic health conditions that individuals reported (see Appendix B). Participants were asked to indicate whether they had been diagnosed with any of the 31 listed conditions and to rate the difficulty each condition causes them from "none" to "severe." Health conditions ranged from potentially fatal (e.g., cancer, heart trouble) to nonfatal (e.g., arthritis, back problems). The Charlson index (see Pompei, Ales \& MacKenzie, 1987) is a valid index that assesses risk of death from comorbid disease by calculating the number and severity of comorbid health conditions. Using this index, responses were first coded for presence (1) or absence (0) of each chronic health condition. In order to calculate the severity of each 
present chronic health condition, responses were then coded as such: (1) "no difficulty," (2) "mild difficulty," (3) moderate difficulty," and (4) "severe difficulty." All 31 present chronic health conditions were summed to create an index of current health status, such that higher scores indicate greater difficulty in dealing with chronic health conditions. In other words, the severity index represented individuals' perceived sense of functional disability that was a result of being diagnosed with a chronic health condition. In the current sample, participants reported having an average of 3.39 chronic health conditions $(\mathrm{SD}=2.36)$ and an average severity composite of $6.32(\mathrm{SD}=5.73)$, indicating that, on average, participants experienced zero or mild difficulty for each of their reported chronic health conditions. The possible severity composite range was from 0 (e.g., reporting no chronic health conditions and no difficulty) to 124 (e.g., reporting all chronic health conditions and severe difficulty). The severity composite range for the current sample was from $0-29$.

\section{Future Time Perspective}

Future Time Perspective (FTP, Lang \& Carstensen, 1994) was measured with a 10-item questionnaire that addressed participants' beliefs about time, opportunities, and goals that may exist in their future. Sample items included statements such as, "Many opportunities await me in the future," and "As I get older, I begin to experience that time is limited" (see Appendix C). Item responses range from (1) "very untrue" to (7) "very true" and the scale is scored such that higher scores indicate an expansive view of time, whereas lower scores indicate a more limited view of time. In the current sample, a mean score of $48.42(\mathrm{SD}=11.94)$ ranging from 10 to 70 , was obtained, indicating a mid-range or moderately open view of the future. The scale had high internal consistency in previous research $(\alpha=.92$; Lang \& Carstensen, 2002) and in the current study $(\alpha=.91)$. 
Internal Health Locus of Control

The Multidimensional Health Locus of Control Scale (MHLC, Wallston, Wallston, \& DeVellis, 1978), a 54-item questionnaire administered in three 18-item forms, addressed individuals' beliefs about whether their health is internally controlled, controlled by others, or are a matter of chance (see Appendix D). The MHLC scale consisted of three dimensions: internality (IHLC) (e.g., "The main thing which affects my health is what I do to myself"); powerful others (PHLC) (e.g., Other people play a big part in whether I stay healthy or become sick"); and chance externality (CHLC) (e.g., "Luck plays a big part in determining how soon I will recover from an illness"). All items were rated on a 6-point Likert scale ranging from (1) "strongly disagree" to (6) "strongly agree".

Because the proposed model focuses only on internal health locus of control, the current study only utilized the internality dimension of the MHLC. Further, Wallston (2005) suggests only using one form (A, B, or C) of the MHLC unless the purpose of the study is to test the validity of the MHLC. In the current study, participants completed the three forms in order (e.g., Form A, Form B, and Form C), thus in order to reduce testing-instrumentation effects, only Form A was included in model testing. Moreover, participants had a strong sense of internal health locus of control over their health, as a mean score of $26.80(\mathrm{SD}=3.60)$, on a scale of $6-36$, was obtained.

In past research, each of the three subscales (i.e., 6-item internality, 6-item powerful others, and 6-item chance externality within each form) was internally consistent, with Cronbach's alphas ranging from .67 to .77 in previous research (Wallston, et al., 1978) and scores ranging from .64 to .77 in the current study. Moreover, the internality subscale was also 
internally consistent, with Cronbach's alphas ranging from .70 to .77 in the current study (e.g., Foram $\mathrm{A}=.70$; Form $\mathrm{B}=.73$; Form $\mathrm{C}=.77$ ).

Health Promoting Behavior

The 52-item Health Promoting Lifestyle Profile II (HPLP II, Walker \& Hill-Polerecky, 1996) assessed the frequency and type of health promoting behaviors in which middle-aged adults engaged (see Appendix E). The HPLP II is composed of a total scale and six subscales to measure various dimensions of heath promotion. The subscales are defined as follows: spiritual growth (9 items) (e.g., "Believe that my life has purpose"); interpersonal relations (9 items) (e.g., "Discuss my problems and concerns with people close to me"); nutrition (9 items) (e.g., "Choose a diet low in fat, saturated fat, and cholesterol"); physical activity (8 items) (e.g., "Follow a planned exercise program"); health responsibility (9 items) (e.g., "Report any unusual signs or symptoms to a physician or other health professional"); and stress management (8 items) (e.g., "Take some time for relaxation each day"). Participants were asked to indicate the frequency with which they engaged in each behavior ranging from (1) "never" to (4) "routinely" and the scale is scored such that higher scores indicate more engagement in health promotion, whereas lower scores indicate less engagement in health promotion. In the current study, a mean health promotion score of $137.12(\mathrm{SD}=22.95)$, on a scale from $52-208$, was obtained, indicating that participants engaged in a moderate amount of health promotion.

The overall scale has been shown to be internally consistent $(\alpha=.94)$ in previous research (Walker \& Hill-Polerecky, 1996) with alpha coefficients for the six subscales ranging from .79 to .87 (Becker \& Arnold, 2004; Walker, Volka, Sechrist, \& Pender, 1988). In past research, construct validity was supported through convergence with the Personal Lifestyle Questionnaire $(r=.68)$, criterion related validity was reported for concurrent measures of 
perceived health status and quality of life $(r=.27$ to .49$)$ and the 3-week test-retest reliability coefficient for the overall scale was .89 (Becker \& Arnold, 2004; Walker \& Hill-Polerecky, 1996). In the current study, the overall scale was internally consistent $(\alpha=.94)$; with alphas ranging from .75 to .86 for the six subscales.

Results

Data Management

Missing Data

Five participants $(4.6 \%)$ had missing data on one or more questions within the Health Promoting Lifestyle Profile II Questionnaire. Participants elected to not answer these questions by checking a box during the online Sona survey that stated "check this box if you do not wish to provide an answer for this question." Widamen (2005) suggests that for item nonresponse, the mean of completed values within that scale for that individual can be substituted because information from that particular subject is still being utilized (i.e., individual mean substitution). As a result, if participants were missing a single item on a given scale, their item mean was used in scale construction. There were no missing data within the other variables of interest.

\section{Outliers}

Prior to analyses, data were inspected for outliers. Outliers were defined as values that fell outside the whiskers of a box plot (Howell, 2002). Values that were identified as outliers were recoded so they were along the whiskers but still on the ends of the distribution. Four values were recoded: two high values for health promoting behavior, one low value for health promoting behavior, and one low value for future time perspective.

\section{Normality}


The distribution of scale scores were examined for normality using skewness and kurtosis values. A distribution was considered significantly skewed if the skew or kurtosis z-score value (e.g., value of skew or kurtosis divided by their standard errors) was greater than 1.96 (Field, 2005). Using this criterion, all of the scales were normally distributed, thus no data transformations were necessary.

\section{Preliminary Analyses}

\section{Descriptive Information}

Descriptive statistics (e.g., mean, standard deviation) for all variables of interest can be found in Table 2. All measures of interest (e.g., future time perspective, internal health locus of control, and health promotion) used a Likert-type scale (e.g., unidimensional scaling), indicating interval level data, thus scale sums were used. Participants had, on average, a chronic condition severity composite of $6.32(S D=5.73)$ and an average of $3.39(\mathrm{SD}=2.35)$ chronic health conditions, indicating they perceived zero to mild functional impairment as a result of each of their reported chronic health conditions. Participants saw their future time as mid-range (i.e., neither limited nor unlimited $)(M=48.42, \mathrm{SD}=11.94)$ and had a strong sense of internal health locus of control over their health, as a mean score of $26.80(\mathrm{SD}=3.60)$ was obtained. Moreover, a total mean health promotion score of $137.12(S D=22.95)$ indicated that participants engaged in few to moderate health promoting behaviors.

\section{Bivariate Correlations}

To determine how the key variables were related, bivariate correlations were examined. Significant correlations between variables provided preliminary support for the hypothesized associations within the path model. Specifically, both age $(r=-.21)$ and adults' perceptions of their functional limitations $(r=-.30)$ were significantly associated with future time perspective. 
Older middle-aged adults were more likely to have a limited future time perspective. Further, the greater the severity of chronic health conditions middle-aged adults perceived, the more likely they were to report having a limited future time perspective. In addition, both future time perspective and internal health locus of control were significantly associated with engagement in health promotion. For example, middle-aged adults with an open-ended future time perspective were more likely to report engagement in health promotion $(r=.47)$. Additionally, middle-aged adults who reported having a stronger internal sense of control over their health were more likely to report engagement in health promotion $(r=.31)$. Table 3 includes the correlation matrix for all variables. For continuous variables, Pearson coefficients are reported; for dichotomous variables, Spearman's rho is reported. For ease of interpretation, gender was coded such that men $=1$ and women $=2$.

Intraclass Correlation

Because twenty-one participants also had their spouse participate in the current study, an intraclass correlation coefficient was calculated to determine agreement between spouses (e.g., 21 dyads). The intraclass correlation coefficient was weak, 0.06 (e.g., Howell, 2002, suggests non independence exists if coefficients are close to 1.00), indicating that data could be considered to be independent.

\section{Analytical Approach: Path Analysis}

\section{Hypothesis and Model Testing}

In addition to the overall fit of the data to the model, each path in Figure 1 represents a specific hypothesis. As seen in Figure 1, age was expected to exert direct effects on health promoting behaviors $(\mathrm{H} 1)$ and indirect effects via its association with future time perspective (H2) and internal health locus of control (H3). Gender was expected to exert direct effects on 
health promoting behaviors (H4) and indirect effects through its association with internal health locus of control (H5). The severity of chronic health conditions was expected to exert indirect effects on health promoting behaviors via its association with future time perspective (H6) and internal health locus of control (H7). Lastly, both future time perspective (H8) and internal health locus of control (H9) were expected to exert direct effects on health promoting behavior.

By utilizing path analyses, all paths (both hypothesized and non-hypothesized) were tested simultaneously, and each path was examined for significance. To assess whether each path was significant, the standardized maximum likelihood estimates (MLE) were inspected. The MLEs were similar to regression coefficients representing the linear influence of common factors on measured variables (Byrne, 2001; Kline, 2005). Statistical significance for each path was determined by examining the Critical Ratio (CR); CR values greater than 1.96 were interpreted as significant at the $p<.05$ level. Moreover, standardized Betas, $\beta$, provided information on the strength of the predictors in the model and indicated the number of standard deviation units the outcome variable would change if the predictor variable changed by one standard deviation (see Byrne, 2001; Kline, 2005).

Planned model revisions included: (1) examining and dropping the non-hypothesized paths based on low MLE values and (2) inspecting the modification indices, which suggest specific paths that can be added to the model in order to improve model fit. After dropping the non-hypothesized paths from the model one at a time, the fit of the data to the model was reanalyzed.

How well the observed data fit the estimated model was determined by inspecting a number of goodness-of-fit statistics. First, a chi-square statistic was used to determine whether the observed data differ from the hypothesized model. A non-significant chi-square indicated 
that the observed model accurately reflected the estimated model. Because the chi-square statistic has significant limitations in model testing (e.g., strongly influenced by sample size and degrees of freedom), a number of goodness-of-fit indices have been developed to better judge the degree of fit between the observed and estimated models (Byrne, 2001). The alternative fit indices used in the current study were the Comparative Fit Index (CFI), the Tucker-Lewis Index (TLI), and the Root Mean Square Error of Approximation (RMSEA). Good model fit was indicated if the CFI was greater than .90 and the TLI was greater than .90 (Kline, 2005). Moreover, model fit was considered acceptable when RMSEA values were less than .08 and was considered a good fit when values were less than .05 (Byrne, 2001).

\section{Preliminary Model}

With the inclusion of paths hypothesized to be non-significant, the tested model (11 tested paths, see Figure 2), resulted in low fit indices and thus indicated a poor fit of the data to the model, $\left.\chi^{2}(\mathrm{df}=4 ; \mathrm{N}=109)=12.447, \mathrm{p}<.05\right), \mathrm{CFI}=.855, \mathrm{TLI}=.458, \mathrm{RMSEA}=.140$. The baseline model also explained a substantial amount of the variance in the dependent variable, health promotion $\left(\mathrm{R}^{2}=.329\right)$. Upon inspection of the MLEs and CR values for each of the 11 paths, model modification started by examining (and later dropping) the non-significant, nonhypothesized paths. The non-hypothesized, non-significant tested path from gender to future time perspective $(\mathrm{CR}=.136, p=.892)$ was dropped first from the model because of its low MLE value (.01) and model fit was reanalyzed (see Table 4 for a list of the CR values, SE estimates, and the unstandardized and standardized betas for the preliminary and hypothesized models; see Table 5 for a list of goodness-of-fit statistics for the preliminary and hypothesized models). Modification indices provided no suggestions. 
For the second tested model, the first non-hypothesized, non-significant path (from gender to future time perspective) had been dropped. Model fit indices suggested some improvement, however the data again fit the model poorly, $\left.\chi^{2}(\mathrm{df}=5 ; \mathrm{N}=109)=12.465, \mathrm{p}<.05\right)$, $\mathrm{CFI}=.872, \mathrm{TLI}=.617, \mathrm{RMSEA}=.118$. Like the first model, the second model also explained a substantial amount of the variance in health promotion $\left(\mathrm{R}^{2}=.327\right)$. After inspection of the MLEs and CR values for each of the ten remaining paths, the second non-hypothesized, non-significant path, (tested path from chronic health conditions to health promotion) $(\mathrm{CR}=-1.162, p=.245)$ was dropped from the model and model fit was reanalyzed. Again, modification indices provided no suggestions.

\section{Hypothesized Model}

Having determined that the two non-hypothesized paths were non-significant, model testing of the hypothesized model began. Results indicated a poor fit of the data to the model, $\chi^{2}$ $(\mathrm{df}=6 ; \mathrm{N}=109)=13.791, \mathrm{p}=<.05), \mathrm{CFI}=.867, \mathrm{TLI}=.667, \mathrm{RMSEA}=.110$. Despite the poor fit, the hypothesized model explained a substantial amount of the variance in health promotion $\left(\mathrm{R}^{2}=.318\right)$

Although none of the indices (e.g., $\chi^{2}$, CFI, TFI, and RMSEA) suggested a good fit of the data to the model, standardized Beta weights for several paths suggested support for five of the nine hypothesized paths. First, hypothesis H2 was supported, as age was negatively associated with future time perspective $(\beta=-0.19)$. In addition, hypothesis $H 4$ was supported $(\beta=0.20)$, as gender was associated with health promotion. Third, hypothesis H6 was supported $(\beta=-0.29)$, as chronic health condition severity was negatively associated with future time perspective. Fourth, hypothesis $\mathrm{H} 8$ was supported $(\beta=0.47)$, as future time perspective was positively associated with health promotion. Next, hypothesis H9 supported $(\beta=0.21)$, as internal health locus of 
control was positively associated with health promotion. Lastly, although hypothesis H1 was not supported (the hypothesized association was in the opposite direction), the path emerged as significant, $(\beta=0.23)$, as age was positively associated with health promotion.

\section{Exploratory Analyses}

Health Promotion Domains. The outcome variable in the previously tested models was a total sum (e.g., collapsing across health promoting subscales) from the Health Promotion Lifestyle Profile II. To assess model fit for each of the six health promotion subscales (e.g., health responsibility, physical activity, nutrition, spiritual growth, interpersonal relations, and stress management), model fit was re-analyzed using each subscale as the outcome variable.

For the health responsibility subscale, results indicated a poor fit of the data to the model, $\left.\chi^{2}(\mathrm{df}=6 ; \mathrm{N}=109)=14.864, \mathrm{p}=<.05\right), \mathrm{CFI}=.725, \mathrm{TLI}=.311, \mathrm{RMSEA}=.117$. Despite the poor fit, the model explained a moderate amount of the variance in health responsibility $\left(\mathrm{R}^{2}\right.$ $=.156$ ). Standardized Beta weights for several paths suggested support for five of the nine paths. Age was negatively associated with future time perspective $(\beta=-.19)$; health condition severity was negatively associated with future time perspective $(\beta=-.29)$; gender was associated with health responsibility $(\beta=0.25)$; age was associated with health responsibility $(\beta=0.20)$; and future time perspective was positively associated with health responsibility $(\beta=0.26)$.

For physical activity, results indicated a poor fit of the data to the model, $\chi^{2}(\mathrm{df}=6 ; \mathrm{N}=$ 109) $=15.999, \mathrm{p}=<.05), \mathrm{CFI}=.712, \mathrm{TLI}=.280, \mathrm{RMSEA}=.124$. In addition, the model explained a moderate amount of the variance in engagement in physical activity $\left(\mathrm{R}^{2}=.142\right)$. Standardized Beta weights for several paths suggested support for four of the nine paths. Age was negatively associated with future time perspective $(\beta=-.19)$; health condition severity was negatively associated with future time perspective $(\beta=-.29)$; future time perspective was 
positively associated with physical activity $(\beta=0.26)$; and internal health locus of control was positively associated with physical activity $(\beta=0.22)$.

For nutrition, results indicated a poor fit of the data to the model, $\chi^{2}(\mathrm{df}=6 ; \mathrm{N}=109)=$ $14.811, \mathrm{p}=<.05), \mathrm{CFI}=.819, \mathrm{TLI}=.547, \mathrm{RMSEA}=.117$. Despite the poor fit, the model explained a moderate amount of the variance in nutrition $\left(\mathrm{R}^{2}=.246\right)$. Standardized Beta weights for several paths suggested support for five of the nine paths. Age was negatively associated with future time perspective ( $\beta=-.19)$; health condition severity was negatively associated with future time perspective $(\beta=-.29)$; gender was associated with nutrition $(\beta=0.27)$; future time perspective was positively associated with nutrition $(\beta=0.38)$; and internal health locus of control was positively associated with nutrition $(\beta=0.17)$.

For spiritual growth, results indicated a poor fit of the data to the model, $\chi^{2}(\mathrm{df}=6 ; \mathrm{N}=$ 109) $=13.884 \mathrm{p}=<.05), \mathrm{CFI}=.898, \mathrm{TLI}=.746, \mathrm{RMSEA}=.110$. Despite the poor fit, the model explained a substantial amount of the variance in spiritual growth $\left(\mathrm{R}^{2}=.432\right)$. Standardized Beta weights for several paths suggested support for six of the nine paths. Age was negatively associated with future time perspective $(\beta=-.19)$; health condition severity was negatively associated with future time perspective $(\beta=-.29)$; gender was associated with spiritual growth $(\beta=.16)$; age was positively associated with spiritual growth $(\beta=.37)$; future time perspective was positively associated with spiritual growth $(\beta=.57)$; and internal health locus of control was positively associated with spiritual growth $(\beta=.19)$.

For interpersonal relations, results indicated a poor fit of the data to the model, $\chi^{2}(\mathrm{df}=$ $6 ; \mathrm{N}=109)=14.539 \mathrm{p}=<.05), \mathrm{CFI}=.822, \mathrm{TLI}=.556, \mathrm{RMSEA}=.115$. Despite the poor fit, the model explained a moderate amount of the variance in interpersonal relations $\left(\mathrm{R}^{2}=.255\right)$. Standardized Beta weights for several paths suggested support for five of the nine paths. Age 
was negatively associated with future time perspective $(\beta=-.19)$; health condition severity was negatively associated with future time perspective $(\beta=-.29)$; gender was associated with interpersonal relations $(\beta=.25)$; age was positively associated with interpersonal relations ( $\beta$ $=.19)$; and future time perspective was positively associated with interpersonal relations $(\beta$ $=.40)$.

For stress management, results indicated a poor fit of the data to the model, $\chi^{2}(\mathrm{df}=6 ; \mathrm{N}=$ 109) $=12.571 \mathrm{p}=.05), \mathrm{CFI}=.803, \mathrm{TLI}=.507, \mathrm{RMSEA}=.101$. In addition, the model explained a small amount of the variance in stress management $\left(\mathrm{R}^{2}=.172\right)$. Standardized Beta weights for several paths suggested support for six of the nine paths. Age was negatively associated with future time perspective ( $\beta=-.19)$; health condition severity was negatively associated with future time perspective $(\beta=-.29)$; gender was associated with stress management $(\beta=.21)$; age was positively associated with stress management $(\beta=.23)$; future time perspective was positively associated with stress management $(\beta=.25)$; and internal health locus of control was positively associated with stress management $(\beta=.19)$.

Multiple Regression. Because the data fit the test model poorly, a hierarchical regression was conducted to evaluate whether the psychological constructs were able to predict health promotion over and above the demographic variables. Demographic variables (e.g., age, gender, perceived chronic health condition severity) were entered in the first step as control variables (i.e., covariates) because based on previous research (see Callahan, 2005; George, 2001; Nelson et al., 2007; Prohaska et al., 2005) they were considered known predictors of health promotion. In the second step, internal health locus of control and future time perspective were entered. Hierarchical regression models allow researchers to determine the change in R-squared values 
between steps, which indicate whether the additional variance accounted for by the variables in each successive step is significantly different than zero.

Results indicated that in the first model (e.g., step 1), age, gender, and perceived chronic health condition severity accounted for a significant amount of the variance in health promotion, $R^{2}=.10, F(3,105)=3.68, p<.01$, indicating that older women who perceived fewer functional limitations were more likely to engage in health promotion. In the second model, internal health locus of control and future time perspective accounted for a significant proportion of health promotion variance after controlling for the effects of age, gender, and perceived chronic health condition severity, $R^{2}$ change $=.25, F(2,103)=19.69, p<.01$ (see Table 6 for a list of the regression coefficients). In other words, the addition of the psychological constructs (e.g., internal health locus of control and future time perspective) caused $R^{2}$ to increase by 0.25 . The second model, which included all five predictors, had a significantly larger $F$ ratio $(19.69, p$ $<.01)$ than the initial model (3.68), indicating that the second model was better able to predict engagement in health promotion.

Four of the five predictors made significant contributions to the regression equation in the second model: age, $t(103)=2.66, p<.01$; gender, $t(103)=2.42, p<.01$; future time perspective, $t(103)=4.94, p<.01$; and internal health locus of control $t(103)=2.68, p<.01$. Overall, these results suggest that when demographic variables were held constant (i.e., similar perceived chronic health condition severities and similar in age), adults were more likely to engage in health promotion if they had a greater sense of internal health locus of control and a more openended future time perspective.

\section{Discussion}

Review of Research Objectives 
The purpose of the current study was to examine factors that influenced engagement in health promotion in a sample of middle-aged community dwelling adults. Specifically, the study had two primary research objectives. The first objective was to examine the relations between demographic variables (e.g., age, gender, and chronic health condition severity), future time perspective, internal health locus of control, and health promotion. The second objective focused on how well future time perspective and health locus of control predicted engagement in health promotion.

\section{Review of Study Findings}

The following section provides a summary of the current study's major findings. In the first section, major findings related to first research objective are highlighted: (a) the associations among age and health promotion, age and future time perspective, and age and internal health locus of control, (b) the associations among gender and health promotion, and gender and internal health locus of control, (c) the associations among chronic health condition severity and future time perspective and chronic health condition severity and internal health locus of control. In the second section, findings related to the second research objective are discussed: (a) the influence of future time perspective on engagement in health promotion and (b) the influence of internal health locus of control on engagement health promotion. The first research question, which addressed both objectives of the study, consisted of nine hypotheses. Each of these hypotheses and whether they were supported will be discussed below.

Overall Fit of the Model. The subsequent discussion focuses on the third, hypothesized model (see Figure 3). Although the data fit the model poorly, the hypothesized model provided support for five of the nine hypotheses. More specifically, age influenced future time perspective (H2), gender influenced health promoting behaviors (H4); the severity of chronic health 
conditions was associated with future time perspective (H6); future time perspective directly influenced health promotion (H8); and internal health locus of control directly influenced health promotion (H9). Lastly, the hypothesized model accounted for a substantial amount of the variance in health promotion (i.e., $30 \%$ ).

The Influence of Age on Health Promotion

Hypothesis H1, that age would be associated with adults' participation in health promotion was supported by the model but emerged in the opposite direction than was hypothesized. Research has consistently noted that participation in physical activity (i.e., a specific health promoting behavior) declines with age and older adults are more likely to have an inactive lifestyle when compared to middle-aged and younger adults (Nelson, 2007; Prohaska et al., 2006; Schutzer \& Graves, 2004); thus it was hypothesized that older middle-aged adults would engage in less health promoting behaviors than younger middle-aged adults. However, results indicated a positive association between age and health promotion, where older middleaged adults engaged in more health promoting behaviors than younger middle-aged adults.

Such a finding is of interest for several reasons. First, health promotion research typically focuses solely on participation in physical activity or exercise, namely because it decreases one's susceptibility to disease and illness and prevents the onset of numerous chronic health conditions (e.g., cardiovascular disease). Findings from the current study suggest that although participation in physical activity may decrease with age due to physical limitations (e.g., arthritis) older middle-aged adults may be choosing to participate in other forms of health promotion (e.g., stress management behaviors). Secondly, even though adults may start to recognize their physical health declines early in midlife (Merrill \& Verbrugge, 1999) and realize the importance of health promoting behaviors, perhaps they are not choosing to adopt these 
behaviors until they approach the transition into old age, when issues related to illness become more salient (Becker \& Arnold, 2004).

Further, because of the current obesity epidemic that exists in Western cultures (see Swinburn et al., 1999) more health care professionals are stressing the importance of prevention and early detection of chronic diseases (Schutzer \& Graves, 2004). As a result, perhaps more adults, regardless of age, are becoming increasingly aware of the importance of health promotion. The Influence of Age on Future Time Perspective

Hypothesis $\mathrm{H} 2$, that age would be associated with future time perspective was supported by the model. Specifically, younger middle-aged adults had a significantly more expansive view of the future than older middle-aged adults, who had a more limited future perspective. Little research has explored future time perspective at midlife (Cate \& John, 2007). Researchers assert that midlife is a time when adults recognize physical declines and are thus reminded of their remaining time to live, which should consequently influence their future time perspective and how many opportunities they feel are available to them in the future (Cate \& John). In other words, as adults become aware of their declining bodies during midlife, their future time perspective becomes limited.

Previous research (Lang \& Carstensen, 2002), suggests midlife is a time for adults to prioritize family and career goals and thus see their future filled with opportunities and as a result, are more likely to have an expansive view of their future in order to fulfill their family and career goals. However, the current finding may also support previous researchers assumptions (Cate \& John, 2007) that midlife is indicative of two concurrent views of future time perspective, with the entrance to midlife signifying a perspective full of opportunities and the exit to midlife signifying a perspective with many limitations. However, longitudinal data is necessary to test this 
assumption. Further, although Löckenhoff and Carstensen (2004) propose that age does not directly influence future time perspective, increasing age is associated with declines in objective physical health, which may directly influence adult's perceptions about their future time.

\section{The Influence of Age on Internal Health Locus of Control}

Hypothesis H3, that older middle-aged adults would have a lower sense of internal control over their health than younger middle-aged adults was not supported. Previous research has asserted that control beliefs decrease with age (Lachman, 2006; Lachman \& Firth, 2004) and although control beliefs are expected to vary by domain in midlife (e.g., increased sense of control in the work domain, decreased sense of control in the child caregiving domain), health related control is assumed to decrease with age (Lachman \& Weaver, 1998a). Likewise, other research suggests that middle-aged adults typically have a greater sense of internal health locus of control when compared to older adults (Lachman \& Firth).

The nonsignificant finding is in accord with findings from Lachman and Weaver (1998a) who suggests that internal health locus of control does not vary by age because healthcare professionals and health campaigns are more proactive in encouraging individuals (regardless of age) to take a larger role in controlling their health. In addition, most Americans believe they can do something to slow their aging process; a belief that is certainly derived from the ubiquitous presence of anti-aging campaigns in western culture (Lachman, 2006; Saucier, 2004). Lastly, the non-significant finding between age and internal health locus may only be generalizable to the Baby Boom cohort. The baby boomers are typically described as competent and knowledgeable, and researchers assume they aspire to optimize the aging process (Lachman 2004); as a consequence, one may expect to find high internal locus of control beliefs in such a sample.

The Influence of Gender on Health Promotion 
Hypothesis H4, that gender would be associated with engagement in health promotion when compared to men was supported by the model. Specifically, women engaged in significantly more health promoting behaviors when compared to men. Although there is an profusion of research to suggest women low participation in physical activity when compared to men (e.g., Hageman, et al., 2005; Rimer, et al., 2001; Seger, et al., 2006) there is some research to suggest that women engage in a wider variety of health promotion behaviors when compared to men. For example, George (2001) reports that women are more likely than men to report their physical and emotional health symptoms to others and are more likely to seek medical care. Furthermore, because women are more likely to talk to health care professionals about their health and are better able to respond to changes in their health status, they are more likely to engage in a variety of health promoting behaviors. Additionally, Callaghan (2005) reports that women have greater self-efficacy beliefs when it comes to self-care practices and thus are more likely to engage in health promotion, when compared to men. Bandura (2004) likewise asserts the importance of self-efficacy in initiating health promotion practices.

This finding is important because it suggests that women are better able to manage their health as they proceed through midlife, when recognizing and responding to physical declines becomes a salient issue (Lachman, 2004). Such a finding may help explain why women's life expectancy is, on average, six years longer than men (Department of Health and Human Services, 2000).

The Influence of Gender on Internal Health Locus of Control

Hypothesis H5, that men would be more likely to have a greater internal sense of control over their health when compared to women was not supported. Previous research, however, has supported the influence of gender on internal health locus of control. For example, results from 
the MIDUS survey suggest that middle-aged men have greater sense of global internal control when compared to middle-aged women. Moreover, in the health domain, women were more likely to have external locus of control than men. Specifically, women felt their health status was influenced more by their physician than their own behaviors (Lachman \& Firth, 2005).

Control beliefs are often examined by domain and during midlife, internal control beliefs often increase in the work and marriage domain but decrease in the child and sex domain (Lachman \& Firth, 2005). Perhaps, the health domain is a multidimensional construct, where men and women differ in some health domains (e.g., physical activity) but not others (e.g., spiritual growth) and collapsing across health domains (e.g., physical activity, spiritual growth, interpersonal relations) does not allow for the detection of such differences.

The Influence of Perceived Functional Limitation on Future Time Perspective

Hypothesis H6, that middle-aged adults' perceived functional limitation due to their chronic health conditions would be associated with their future time perspective was supported by the model. Specifically, the more difficulty that middle-aged adults perceived their chronic health conditions to be causing, the more limited their future time perspective. In other words, healthier adults (e.g., zero or less severe chronic health conditions) were more likely to perceive their future time as expansive when compared to middle-aged adults who perceived their health conditions to be more severely inhibiting their daily functioning. This is in line with previous research (Carstensen \& Frederick, 1998) that demonstrated that both younger and older adults who were HIV positive had similar future time perspectives; in particular, all HIV positive adults, regardless of age, saw fewer opportunities in the future. Other research is in accord with this finding; Zanjani and colleagues (2006) assert that having a chronic health condition influences 
individuals' perceived vulnerability to disease and illness, which may consequently influence future time perspective.

This finding is of interest because it highlights the importance of how individuals' health status (e.g., being diagnosed with a chronic health) can significantly influence their perception of their future. Age may not be the sole predictor of future time perspective. Being diagnosed with a chronic health condition may serve as a stark reminder for adults' perceptions of how many opportunities they feel will be available to them in the future.

Furthermore, how individuals perceive their future time influences the types of goals people choose for themselves (Lang \& Carstensen, 2002). For example, individuals with few functional limitations due to their chronic health conditions may be more likely to have an expansive view and will choose goals that optimize the future (e.g., adherence to exercise programs) and will consequently engage in health promotion (Löckenhoff \& Carstensen, 2007). However, currently 49 million Americans live with a chronic disease (Stuifbergen, 2006) and, although incidence rates increase with age (Piazzaet al., 2007) it is estimated that the onset of such diseases will start to emerge at younger ages because of the current obesity epidemic. As a result, numerous adults may be diagnosed with a chronic health condition earlier in life and may be less likely to prioritize goals that optimize the future because they perceive their future time as limited.

The Influence of Perceived Functional Limitation on Internal Health Locus of Control

Hypothesis H7, that middle-aged adults who perceived less severe functional limitations would have a greater internal sense of control over their health when compared to middle-aged adults who perceived more severe functional limitations was not supported. Results from Lachman and Weaver (1998a) suggest a negative association between chronic health conditions 
and internal health locus of control beliefs. The more chronic health conditions middle-aged adults reported experiencing, the less control the felt they had over their health. The nonsignificant finding is of interest because it suggests that adults' perceived chronic health condition severity may not be an important predictor of control beliefs; the number of reported health conditions may simply warrant sufficient power in influencing individual's internal health locus of control beliefs.

\section{The Influence of Future Time Perspective on Health Promotion}

Hypothesis H8, that middle-aged adults' future time perspective would be associated with health promotion was supported by the model. Specifically, middle-aged adults who perceived their future as relatively open-ended engaged in more health promoting behaviors than middleaged adults who perceived their future time as limited. Although research on the association between future time perspective and health promotion is scarce, this finding is in accord with researchers who suggest that individuals' behaviors are influenced by their goals, which are strongly influence by future time perspective (Löckenhoff \& Carstensen, 2004). More specifically, individuals who viewed their future as relatively open with opportunities, chose goals (hypothetically) that optimized their future, and consequently, engaged in more health promotion.

In the health domain, Löckenhoff and Carstensen (2004) suggest that when middle-aged adults who view their future time as open ended and thus full of opportunities, goals aimed at optimizing the aging process are prioritized and adults are more likely to engage in health promoting behaviors such as seeking out health information from their doctor and adhering to a physical activity regimen. The significant finding likewise supports this idea. Moreover, middleaged adults who view their future as limited do not prioritize goals aimed at optimizing the future. 
Instead, these adults are more concerned with deriving an emotional meaning from life (Cate \& John, 2007), are less concerned with health promotion and thus prioritize emotionally meaningful goals (e.g., avoid negative interactions with primary care physician, seek out emotional interactions).

\section{The Influence of Internal Health Locus of Control on Health Promotion}

Hypothesis H9, that middle-aged adults who had a stronger internal sense of control would more likely engage in more health promoting behaviors when compared to middle-aged adults who had a weaker internal sense of control was supported by the model. Specifically, middle-aged adults who had a greater internal sense of control over their health were more likely to engage in health promoting behaviors. This finding is in accord with past research that suggests that those who believe they can control their health outcomes are more likely to experience greater well-being because they are more likely to engage in healthy promotion (Lachman \& Firth, 2004; Ziff et al., 1995), experience fewer chronic illnesses, and report better self-rated health (Lachman, 2006). Additionally, these findings may also lend support to the assumption that midlife is a time of increased power and control, regardless of the domain of interest (Clark-Plaskie \& Lachman, 1999).

Researchers assert that maintaining a high internal sense of control is imperative for successful aging because it allows for adults to overcome the negative experiences that are typically associated with the aging process (Lachman \& Firth, 2004). As a result, maintaining a high sense of internal control becomes important in midlife, when adults start to experience the physical changes that emerge during this developmental period. In other words, a high internal sense of control may act as a buffer during midlife (Lachman \& Firth), because it allows for adults to persevere and deal with the multiple social roles and responsibilities that middle-aged 
adults are assumed to be balancing in the while concurrently experiencing the physical and psychological changes that accompany aging (Lachman, 2004).

\section{Summary}

The current study suggests that the tested data fit the hypothesized model poorly, even though six of the nine paths were supported. Exploratory model revisions indicated that model fit was considered satisfactory only when the three non-significant paths hypothesized to be associated with internal health locus of control were dropped from the model (see Table 5).

When examining the two psychological constructs, future time perspective and internal health locus of control, engagement in health promoting behaviors was more strongly influenced by future time perspective ( $\beta=.47$ ) than internal health locus of control $(\beta=.21)$. As a result, future time perspective may be a useful construct to include in health intervention research if researchers are attempting to understand the underlying mechanisms of health behavior change. However, whether it is useful to intervene with future time perspective remains unclear because it is uncertain whether health practitioners can alter one's future time perspective with intervention techniques.

Because future time perspective and internal health locus of control did not emerge as significant mediators in explaining the relation between demographic variables and engagement in health promotion in the tested path analysis, a hierarchical regression was conducted to further investigate the association among psychological constructs and health promotion. Engagement in health promotion was best predicted when both future time perspective and internal health locus of control were included with demographics in model testing. In addition, both constructs significantly contributed to the regression equation. Furthremore, about 70 percent of the variability in health promotion was attributable to the effects of the two psychological constructs 
and only 30 percent of the variability in health promotion was attributable to the effects of age, gender, and perceived functional limitations. Results suggest that although older women who perceive fewer functional limitations are more likely to engage in health promotion, psychological variables predict health promotion above and beyond demographics. More specifically, adults who had a greater internal health locus of control and a more open-ended view of their future were more likely to engage in health promoting behaviors than adults with lesser internal health locus of control and limited view of their future.

Also of interest were the three non-significant relations that were hypothesized to be associated with internal health locus of control (H3, H5, and H7). These non-significant paths warrant attention, though, because they may lend support for the need to consider internal health locus of control as a person variable (e.g., personality characteristic) that is stable and not necessarily as an outcome variables that is associated with other demographic variables (e.g., age, gender, health condition status).

The results suggest that an intervention designed to increase health promotion might prove successful if future time perspective is incorporated into model testing. More specifically, the model indicated that future time perspective was directly associated with health promotion as middle-aged adults who perceived their future as unlimited engaged in more health promoting behaviors. In addition, age and chronic health condition severity were indirectly associated with health promotion through their association with future time perspective such that younger middle-aged adults and those with less severe chronic health conditions had a more expansive view of their future. Because midlife is a time when physical declines start to emerge, and health condition severity emerged significantly associated with future time perspective, knowing participants' health status seems important in informing future intervention work. 


\section{Domains of Health Promotion}

Because there is research to suggest that engagement in health promotion varies by domain (e.g., physical activity, nutrition) (Zanjani et al., 2006), and internal locus of control beliefs vary by domain (Lachman \& Firth, 2005) of interest was whether model fit varied across the six health promotion subscales of the HPLP II (e.g., physical activity, nutrition, health responsibility, interpersonal relations, stress management, and spiritual growth). Although the data fit each of the models poorly, several of the paths emerged significant within each health promotion domain.

For all six tested models, age negatively influenced future time perspective; older middleaged adults saw their future as limited compared to younger middle-aged adults, who viewed their future as unlimited. Moreover, the severity of chronic health conditions negatively influenced future time perspective; middle-aged adults who were experiencing more severe chronic illnesses reported having a more limited view of their future than middle-aged adults who were experiencing less severe chronic illness.

Interestingly, future time perspective was positively associated with engagement in each of the six health promotion domains. Middle-aged adults who had an expansive view of their future, and thus hypothetically interested in optimizing their aging process (Löckenhoff \& Carstensen, 2004), were more likely to engage in health responsibility behaviors, physical activity, nutrition behaviors, spiritual growth behaviors, interpersonal relation behaviors, and stress management techniques. Internal health locus of control was associated with engagement in four of the six health promotion domains (e.g., physical activity, nutrition, spiritual growth, and stress management). Moreover, inspection of the standardized beta weights for each health 
promotion domain indicated that future time perspective was more strongly associated with the health outcomes ( $\beta=.25$ to .57$)$ than internal health locus of control $(\beta=.17$ to .22$)$.

Lastly, the influence of age and gender on health promotion varied by domain. Consistent with previous research, when compared to men, women were more likely to engage in each domain of health promotion except physical activity. Age influenced participation in four health promotion domains, such that older middle-aged adults were more likely to engage in health responsibility behaviors, spiritual growth behaviors, interpersonal relation behaviors, and stress management techniques when compared to younger middle-aged adults. Age did not influence participation in physical activity or nutrition behaviors.

These findings suggest that midlife is a time when adult's perceptions of how many opportunities await for them in the future strongly influences their decision to engage in health promoting behaviors. Because midlife is a time when physical declines start to emerge and adults are reminded of the negative consequences associated with the aging process (Lachman, 2004, Merrill \& Verbrugge, 1999), perhaps the emergence of such declines triggers stress that strongly influences middle-aged adults' future time perspective. Thus, researchers should consider using socioemotional selectivity theory and future time perspective as a conceptual framework for future work aimed at increasing health promoting behaviors at midlife.

\section{Limitations and Future Directions}

The findings from the current study add to the small, yet growing literature of midlife development regarding the importance of considering psychological constructs when examining engagement in health promotion. However, a number of limitations must be considered when interpreting the results and possible opportunities for future research.

\section{Sampling}


It is possible that the current study would not be replicable in a more diverse sample of middle-aged adults. First, the participants were quite affluent and high functioning; over $70 \%$ reported earning a college degree (22\% of those earning graduate degree) and over $60 \%$ reported a total income of over $\$ 75,000$ (40\% reported an income greater than $\$ 100,000)$. Secondly, 95\% of the sample was White, which limits the generalizability to other ethnic or racial groups. Because a majority of the participants were residents of Northeastern and Mid-Atlantic regions, the current findings may not generalize to other regions in the United States. Additionally, out of 842 middle-aged adults who were contacted to participate in the study, only 167 participants responded to the recruitment postcards. Thus, data on non-responders were not available and the sample in the current study may have been biased such that those who were more educated and had more resources were more likely to respond to the recruitment ads and participate in the study. Moreover, the title of the online SONA survey, "Health Promoting Behavior Study" may have increased selection bias. In other words, perhaps participants who engaged in healthy lifestyles were more likely to choose and participate in the Health Promoting Behavior Study because it was attractive and seemed relevant to them when compared to less healthy participants.

Future research should attempt to replicate the tested model in a more diverse sample of middle-aged adults. For example, there is a growing body of literature that examines health promotion (typically physical activity behaviors) in samples of adults who are experiencing a specific chronic health condition (e.g., breast cancer diagnosis, heart attack episode). Little research examines how comorbidity may influence engagement in health promotion. Perhaps the model could better inform health condition specific health interventions by testing the model with samples of middle-aged adults with specific chronic health conditions.

\section{Measurement}


Another limitation of the current study was related to measurement issues. All of the measures were self-report measures. Although all of the selected measures were carefully selected based on previous research; in general, a number of limitations are associated with selfreport measures. For example, there is an over-reliance on episodic recall, closed-ended items often force people into choosing an alternative even if they feel the best answer is not included, and, lastly, participants are more likely to overly report social desirable behaviors (e.g., I frequently engage in regular exercise) when answering self-report items (Krosnick, 1999; Schwarz, 1999).

Because it is important to validate self-report data on objective measures of the same construct, future research should address these shortcomings by including multiple measurement techniques. With respect to the construct of health promotion, there are a number of objective measures of physical activity (e.g., accelerometers) that are being widely implemented in health promotion research.

\section{Study Design}

Given the cross-sectional nature of the data in the current study, the typical caveat must be acknowledged. Cross-sectional data are limited to group averages and do not allow for the examination of intraindividual changes or causal interpretations. Thus, within the current study's path analysis framework, causa; links could not be determined, only estimated conclusions regarding development could be made (Baltes, Reese, \& Nessleroad, 1998).

In order to fully understand how adults enter midlife and progress until old age, future research must utilize longitudinal methods. For example, longitudinal data could help explain how changes in psychological constructs over time influence variability in health promotion. As 
previously mentioned, cohort effects may be present; thus future research that implements a cross-sequential design, could clarify the presence of these effects.

\section{Conclusion}

The current study addressed the importance of considering personal and psychological factors in the study of health promotion at midlife. The first objective examined the relations the relations among demographic variables (e.g., age, gender, and severity of chronic health conditions), future time perspective, internal health locus of control, and engagement in health promoting behaviors. Results indicated that age and gender were associated with engagement in health promotion. Moreover, age and chronic health condition severity were associated with future time perspective. Additionally, the influence of age and gender varied depending on the health domain of interest. Age and gender both influenced engagement in health responsibility behaviors, spiritual growth, interpersonal relations, and stress management techniques.

The second objective focused on how well future time perspective and health locus of control were associated with engagement in health promotion. Results indicated that both psychological constructs significantly influenced engagement in health promotion. In addition, future time perspective significantly influenced middle-aged adults' engagement in each of the six health promotion domains; internal health locus of control influenced engagement in four of the six health promotion domains. Moreover, exploratory results suggest that when demographic variables are held constant, middle-aged adults are more likely to participate in health promotion if they have a greater internal health locus of control and have a more open-ended view of their future.

The current study provides a basis for further investigation of the factors that are related to health promotion at midlife. The results lend support to the notion that future time perspective 
is an important construct to consider when attempting to understand why middle-aged adults choose to engage in a variety of health promoting behaviors and may better inform future health interventions. Additional research is needed to identify the relations among personal and psychological factors at midlife in order to promote engagement in health promoting behaviors. 


\section{References}

Adams, P. F., Lucas, J. W., \& Barnes, P. M. (2008). Summary of health statistics for the U.S. population: National health interview survey, 2006. U.S. Department of Health and Human Services Vital and Health Services, 10, 2-9.

Baltes, P. B. (1987). Theoretical propositions of life-span developmental psychology: On the dynamics between growth and decline. Developmental Psychology, 23, 631-626.

Baltes, P. B., Reese, H. W., \& Nesselroade, J. R. (1988). Life-span developmental psychology: Introduction to research methods. Hillsdale, NJ: Erlbaum.

Bandura, A. (2004). Health promotion by social cognitive means. Health Education and Behavior, 31, 143-164.

Baron, R. M. \& Kenny, D. A. (1986). The moderator-mediator variable distinction in social psychological research: Conceptual, strategic, and statistical considerations. Journal of Personality and Social Psychology, 51, 1173-1182.

Becker, C. M., \& Arnold, W. (2004). Health promoting behaviors of older Americans versus young and middle-aged adults. Educational Gerontology, 30, 835-844.

Blanchard, C. M., Denniston, M. M., Baker, F., Ainsworth, S. R., Courneya, K. S., Hann, D. M., et al. (2003). Do adults change their lifestyle behaviors after a cancer diagnosis? American Journal of Health Behavior, 27, 246-256.

Breslow, L. (1999). From disease prevention to health promotion. Journal of the American Medical Association, 281, 1030-1034.

Brim, O. G., Ryff, C. D., \& Kessler, R. C. (2004). The MIDUS national survey: An overview. In O. G. Brim, C. D. Ryff, and R. C. Kessler (Eds.), How healthy are we? A national study of well-being at midlife (pp. 1-34). Chicago: University of Chicago Press. 
Byrne, B. M. (2001). Structural equation modeling with AMOS: Basic concepts, applications, and programming. Mahwah, NJ: Lawrence Erlbaum Associates.

Callaghan, D. (2005). Healthy behaviors, self-efficacy, self-care, and basic conditioning factors in older adults. Journal of Community Health Nursing, 22, 169-178.

Carstensen, L. L., \& Fredrickson, B. L. (1998). Influence of HIV status and age on cognitive representations of others. Health Psychology, 17, 494-503.

Carstensen, L. L., Isaacowitz, D. M., \& Charles, S. T. (1999). Taking time seriously: A theory of socioemotional selectivity. American Psychologist, 54, 165-181.

Cate, R. A., \& John O. P. (2007). Testing models of the structure and development of future time perspective: Maintaining a focus on opportunities in middle age. Psychology and Aging, 22, 186-201.

Centers for Disease Control (2001). Physical Activity and Health. Retrieved March 20, 2009, from http://www.cdc.gov/nccdphp/sgr/summary.htm.

Chad, K. E., Reeder, B. A., Harrison, E. L., Ashworth, N. L, Sheppard, S. M., Schultz, S. L., et al. (2005). Profile of physical activity levels in community-dwelling older adults. Medicine \& Science in Sports \& Exercise, 37, 1774-1784.

Charlson, M. E., Pompei, P., Ales, K. L., \& MacKenzie, C. R. (1987). A new method of classifying prognostic comorbidity in longitudinal studies: development and validation. Journal of Chronic Disease, 40, 373-383

Clark-Plaskie, M., \& Lachman, M. E. (1999). The sense of control in midlife. In S.L. Willis \& J.D. Reid (Eds.), Life in the middle: Psychological and social development in middle-age (pp. 3-24). London: Academic Press. 
Colcombe, S., \& Kramer, A. F. (2003). Fitness effects on the cognitive function of older adults: A Meta-Analytic study. Psychological Science, 14, 125-130.

Erikson, E. (1982). The life cycle completed: A review. New York: Norton.

Field, A. (2005). Discovering statistics using SPSS. Thousand Oaks, CA: Sage.

Fung, H. H., Carstensen, L. L., \& Lutz, A. M. (2002). Influence of time on social preferences: Implications for life-span development. Psychology and Aging, 14, 595-604.

George, L. K. (2001). The social psychology of health. In R.H. Binstock \& L.K. George (Eds.), Handbook of aging and the social sciences, (pp. 217-237). London: Academic Press.

Gosseling, C. A., Cox, D. L., McClure, S., J., \& DeJong, M. L. (2008). Ravishing or ravished: Women's relationships with women in the context of aging and western beauty culture. International Journal of Aging and Human Development, 66, 307-327.

Grzywacz, J. G. (2000). Work-family spillover and health during midlife: Is managing conflict everything? American Journal of Health Promotion, 14, 236-243.

Grzywacz, J. G., \& Keyes, C. L. M. (2004). Toward health promotion: Physical and social behaviors in complete health. American Journal of Health Behavior, 28, 99-111.

Hageman, P. A., Walker, S. N., Pullen, C. H., Boeckner, L. S., \& Oberdorfer, M. K. (2005). Physical activity and fitness among midlife and older rural women. Journal of Aging and Physical Activity, 13, 327-342

Holmbeck, G. N. (1997). Toward terminological, conceptual, and statistical clarity in the study of mediators and moderators: Examples from the child-clinical and pediatric psychology literatures. Journal of Counseling and Clinical Psychology, 65, 599-610. 
Horvath, T. B. \& Davis, K. L. (1990). Central nervous system disorders in aging. In E. L. Schneider \& J. W. Rowe (Eds.), The handbook of biology and aging (pp. 306-329). San Diego: Academic Press.

Howell, D. C. (2002). Statistical methods for psychology. Pacific Grove, CA: Wadsworth Group. Katchadorian, H. (1987). Fifty: Midlife in perspective. New York: W. H. Freeman.

Kline, R. B. (2005). Principles and practice of structural equation modeling. New York, NY: Guilford Press.

Krosnick, J. A., (1999). Survey Research. Annual Review of Psychology, 50, 537-567.

Kumanyika, S., Jeffery, R.W., Morabia, A., Rittenbaugh, C., \& Antipatis, V.J. (2002). Obesity prevention: The case for action. International Journal of Obesity, 26, 425-436.

Lachman, M. E. (2004). Development in midlife. Annual Review of Psychology, 55, 305-331.

Lachman, M.E. (2006). Perceived control over aging-related declines: Adaptive beliefs and behaviors. Current Directions in Psychological Science, 15, 282-286.

Lachman M. E., \& Firth, K. M. P. (2004). The adaptive value of feeling in control during midlife. In O. G. Brim, C. D. Ryff, \& R. C. Kessler (Eds.), How healthy are we? A national study of well-being at midlife (pp. 320-349). Chicago, IL: The University of Chicago Press.

Lachman, M. E., \& James, J. B. (1997). Charting the course of midlife development: An overview. In M. E. Lachmam \& J. B. James (Eds.), Multiple Paths of Midlife Development (pp. 1-17). Chicago, IL: The University of Chicago Press.

Lachman, M. E., \& Weaver, S. L. (1998). Sociodemographic variations in the sense of control by domain: Findings from the MacArthur Studies of Midlife. Psychology and Aging, 13, $553-562$.

Lachman, M. E., \& Weaver, S. L. (1998). The sense of control as a moderator of social class 
differences in health and well-being. Journal of Personality and Social Psychology, 74, $763-773$.

Lang, F. R., \& Carstensen, L. L. (2002). Time counts: Future time perspective, goals, and social relationships. Psychology and Aging, 17, 125-139.

Leventhal, H., Rabin, C., Leventhal, E. A., \& Burns, E. (2001). Health risk behaviors and aging, InJ. R. Birren \& K. W. Schaie (Eds.), Handbook of psychology and aging (pp.186-214). London: Academic Press.

Löckenhoff, C. E., \& Carstensen, L. L. (2004). Socioemotional selectivity theory, aging, and health: The increasingly delicate balance between regulating emotions and making tough choices. Journal of Personality, 72, 1395-1424.

Löckenhoff, C. E., \& Carstensen, L. L. (2007). Aging, emotion and health-related decision strategies: Motivational manipulations can reduce age differences. Psychology and Aging, 22, 134-146.

Longest, B. B. (2006). Impact of health policy. In Health policymaking in the United States (Ch 2, pp. 33-73).

Merrill, S. S., \& Verbrugge, L. M. (1999). Health and disease in midlife. In S. L. Willis \& J. D. Reid (Eds.), Life in the middle: Psychological and social development in middle-age (pp. 78-104). London: Academic Press.

Moen, P., \& Wethington, E. (1999). Midlife development in a life course context . In S.L. Willis \& J.D. Reid (Eds.), Life in the middle: Psychological and social development in middleage (pp. 3-24). London: Academic Press.

Nelson, M. E., Rejeski, W. J., Blair, S. N., Duncan, P. W., Judge, J. O., King, A. C., et al. (2007). Physical activity and public health in older adults: Recommendation from the American 
College of Sports Medicine and the American Heart Association. Journal of the American College of Sports Medicine, 7, 1435-1445.

Piazza, J. R., Charles, S. T., \& Almeida, D. M. (2007). Living with chronic health conditions: Age differences in affective well-being. Journals of Gerontology, 62B, 313-321.

Prohaska, T., Belansky, E., Belza, B., Buchner, D., Marhsall, V., McTigue, K., et al. (2006). Physical activity, public health, and aging: Critical issues and research priorities. Journals of Gerontology, 61B, 267-273.

Rimer, B. K., McBride, C. M., \& Crump, C. (2001). Women's health promotion. In A. Baum, T. A. Revenson, \& J. E. Singer (Eds.), Handbook of health psychology (pp. 519-539). Mahwah, NJ: Lawrence Erlbaum Associates, Inc.

Rodin, J. (1986) Health, control, and aging. In M. M. Baltes \& P. B. Baltes (Eds.), The Psychology of Control and Aging (139-165). Hillsdale, NJ: Lawrence Erlbaum Associates, Inc.

Rosenberg, S. D., Rosenberg, H. J., \& Farrell, M. P. (1999). The midlife crisis revisted. In S. L. Willis \& J. D.Reid (Eds.), Life in the middle: Psychological and social development in middle-age (pp. 47-73). London: Academic Press.

Saucier, M. G. (2004). Midlife and beyond: Issues for aging women. Journal of Counseling and Development, 82, 420-425.

Schutzer, K. A., \& Graves, B. S. (2004). Barriers and motivators to exercise in older adults. Preventive Medicine, 39, 1056-1061.

Schwarz, N. (1999). Self-reports: How the questions shape the answers. American Psychologist, 54, 93-105. 
Segar, M., Spruijt-Metz, D., \& Nolen-Hoeksema, S. (2006). Go figure? Body-shape motives are associated with decreased physical activity participation among midlife women. Sex Roles, 54, 175-187.

Skaff, M. M. (2006). The view from the driver's seat: Sense of control in the baby boomers at midlife. In S. K. Whitbourne \& S. L. Willis (Eds.), The baby boomers grow up (pp. 185204). Mahwah, New Jersey: Lawrence Erlbaum Associates.

Skaff, M. M. (2007). The sense of control and health: A dynamic duo in the aging process. In C. M. Aldwin, C. L. Park \& A. Spiro (Eds.), Handbook of Health Psychology and Aging (pp. 186-209). New York, New York: Guilford Press.

Soederberg Miller, L. M., \& Lachman, M. E. (2000). Cognitive performance and the role of control beliefs in midlife. Aging, Neuropsychology, and Cognition, 7, 69-85.

Stuifbergen, A. K. (2006). Building health promotion interventions for persons with chronic disabling conditions. Family Community Health, 29, 28-34.

Swinburn, B., Egger, G., Raza, F. (1999). Dissecting obesogenic environments: The development and application of a framework for identifying and prioritizing environmental interventions for obesity. Preventive Medicine, 29, 563-570.

Swinburn, B., Gill, T., \& Kumanyika, S. (2005). Obesity prevention: A proposed framework for translating evidence into action. Obesity Reviews, 6, 23-33.

Traywick, L. S., \& Schoenberg, N. E. (2008). Determinants of exercise among older female heart attack survivors. Journal of Applied Gerontology, 27, 52-77.

U.S. Department of Health and Human Services. (2007). Overweight and obesity: What can you do. Retrieved April 27, 2007, from http://www.surgeongeneral.gov/ topics/obesity/calltoaction/fact_whatcanyoudo.htm. 
U.S. Department of Health and Human Services. (2007). New CDC study finds no increase in obesity among adults; but levels still high. Retrieved March 1, 2009, from http://www.cdc.gov/ nchs/pressroom/07newsreleases/obesity.htm

Walker, S. N. \& Hill-Polerecky, D. M. (1996). Psychometric evaluation of the Health-Promoting Lifestyle Profile II. Unpublished manuscript, University of Nebraska Medical Center.

Walker, S. N., Volkan, K., Sechrist, K. R., \& Pender, N. J. (1988). Health-promoting life styles of older adults: Comparisons with young and middle-aged adults, correlates and patterns. Advances in Nursing Science, 11, 76-90.

Wallston, K.A. (2005). The validity of the multidimensional health locus of control scales, Journal of Health Psychology, 10, 623-631.

Wallston, K. A., Wallston, B. S., \& DeVellis, R. (1978). Development of the multidimensional health locus of control (MHLC) scales. Health Education Monographs, 6, 160-170

Wethington, E. (2000). Expecting stress: Americans and the "midlife crisis." Motivation and Emotion, 24, 85-103.

Widamen, K. F. (2005). Missing data: What to do with or without them. In Monographs of the Society for Research in Child Development, 71, 42-64.

Wister, A., \& Romeder, Z. (2002). The chronic illness context and change in exercise self-care among older adults: A longitudinal analysis. Canadian Journal on Aging, 21, 521-534.

Zanjani, F. A. K., Schaie, K. W., \& Willis, S. L. (2006). Age group and health status effects on health behavior change. Behavioral Medicine, 32, 36-46.

Ziff, M. A., Conrad, P., \& Lachman, M. E. (1995). The relative effects of perceived personal control and responsibility on health and health-related behaviors in young and middleaged adults. Health Education Quarterly, 22, 127-142. 
Table 1

Descriptive Statistics for Demographic Variables

\begin{tabular}{|c|c|c|c|c|}
\hline Variable & $\mathrm{M}$ & $\mathrm{SD}$ & Min & Max \\
\hline Age (years) & 49.94 & 4.96 & 40 & 66 \\
\hline Number of Doctor Visits (past 12 months) & 4.1 & 4.68 & 0 & 30 \\
\hline Number of People in Household & 3.11 & 1.23 & 1 & 6 \\
\hline Hours of Paid Work (per Week) & 34.4 & 18.02 & 0 & 80 \\
\hline Hours of Unpaid Work (per Week) & 2.8 & 5.64 & 0 & 40 \\
\hline Number of Chronic Health Conditions & 3.39 & 2.35 & 0 & 9 \\
\hline Variable & $\mathrm{N}$ & $\%$ & & \\
\hline \multicolumn{5}{|l|}{ Gender } \\
\hline Male & 33 & 30.3 & & \\
\hline Female & 76 & 69.7 & & \\
\hline \multicolumn{5}{|l|}{ Ethnicity } \\
\hline African American & 2 & 1.8 & & \\
\hline Asian / Pacific Islander & 1 & 0.9 & & \\
\hline Caucasian / White & 103 & 94.5 & & \\
\hline Latino / Hispanic & 1 & 0.9 & & \\
\hline \multicolumn{5}{|l|}{ Marital Status } \\
\hline Cohabitating / Living w Partner & 1 & 0.9 & & \\
\hline Married & 88 & 80.7 & & \\
\hline Divorced & 13 & 11.9 & & \\
\hline Remarried After Divorce & 5 & 4.6 & & \\
\hline \multicolumn{5}{|l|}{ Education } \\
\hline $9^{\text {th }}$ to $11^{\text {th }}$ grade & 1 & 0.9 & & \\
\hline High school diploma & 28 & 25.7 & & \\
\hline College - Degree & 55 & 50.5 & & \\
\hline Graduate - Degree & 24 & 22 & & \\
\hline \multicolumn{5}{|l|}{ Income } \\
\hline Less than $\$ 25,000$ & 3 & 2.8 & & \\
\hline$\$ 25,000-\$ 49,999$ & 15 & 13.8 & & \\
\hline$\$ 50,000-\$ 74,999$ & 17 & 15.6 & & \\
\hline$\$ 75,000-\$ 99,999$ & 26 & 23.9 & & \\
\hline$\$ 100,000+$ & 43 & 39.4 & & \\
\hline
\end{tabular}


Table 1 (continued)

\begin{tabular}{|c|c|c|}
\hline Variable & $N$ & $\%$ \\
\hline \multicolumn{3}{|l|}{ Take Vitamin Supplements } \\
\hline Yes & 71 & 65.1 \\
\hline No & 37 & \\
\hline \multicolumn{3}{|l|}{ Insurance } \\
\hline Public & 26 & 23.9 \\
\hline Private & 76 & 69.7 \\
\hline No insurance & 5 & 4.6 \\
\hline \multicolumn{3}{|l|}{ Trust Health Care Provider } \\
\hline A little & 33 & 30.3 \\
\hline A great deal & 75 & 68.8 \\
\hline \multicolumn{3}{|c|}{ Physically Able to access to Health } \\
\hline \multicolumn{3}{|c|}{ Care } \\
\hline Very easily & 39 & 35.8 \\
\hline Moderately easy & 36 & 33 \\
\hline Easy & 21 & 19.3 \\
\hline Hard & 1 & 0.9 \\
\hline Moderately hard & 10 & 9.2 \\
\hline Very hard & 0 & 0 \\
\hline \multicolumn{3}{|l|}{ Body Mass Index (BMI) } \\
\hline Underweight & 0 & 0 \\
\hline Normal Weight & 28 & 25.7 \\
\hline Overweight & 44 & 40.4 \\
\hline Obese & 30 & 27.5 \\
\hline \multicolumn{3}{|l|}{ Chronic Health Conditions } \\
\hline Arthritis & 41 & 37.6 \\
\hline Heart Trouble & 13 & 11.9 \\
\hline Back Problems & 41 & 37.6 \\
\hline Breathing Problems & 18 & 16.5 \\
\hline Diabetes & 6 & 5.5 \\
\hline High Blood Pressure & 30 & 27.5 \\
\hline Cancer & 1 & 0.9 \\
\hline Glaucoma & 1 & 0.9 \\
\hline Cataracts & 4 & 3.7 \\
\hline Nervousness/Tension & 37 & 33.9 \\
\hline Sleep problems & 41 & 37.6 \\
\hline Headaches & 45 & 41.3 \\
\hline Parkinson's Disease & 1 & 0.9 \\
\hline
\end{tabular}


Table 1 (continued)

\begin{tabular}{lrr}
\hline \multicolumn{1}{c}{ Variable } & $N$ & $\%$ \\
\hline Hardening of the Arteries & 1 & 0.9 \\
Stomach Ulcers & 3 & 2.8 \\
Stroke / Effects of stroke & 1 & 0.9 \\
Paralysis & 2 & 1.8 \\
Circulation Trouble & 6 & 5.5 \\
Asthma & 10 & 9.2 \\
Broken Hip & 1 & 0.9 \\
Other Broken Bones & 6 & 5.5 \\
Bladder Problems & 17 & 15.6 \\
Gall Bladder Trouble & 6 & 5.5 \\
Kidney Trouble & 4 & 3.7 \\
Anemia & 5 & 4.6 \\
Emphysema & 1 & 0.9 \\
Epileptic seizures & 0 & 0 \\
Pnemonia & 1 & 0.9 \\
Serious Hearing Problems & 16 & 14.7 \\
Serious Vision Problems & 11 & 10.1 \\
\hline
\end{tabular}


Table 2

Means and Standard Deviations for Key Study Variables

\begin{tabular}{lrrrrrr}
\hline Variable & \# Items & \multicolumn{1}{c}{$\alpha$} & \multicolumn{1}{c}{ M } & \multicolumn{1}{c}{ SD } & Min & Max \\
\hline Chronic Health Condition Severity & 31 & 0.72 & 6.32 & 5.73 & 0 & 29 \\
Future Time Perspective & 10 & 0.91 & 48.42 & 11.94 & 10 & 70 \\
Health Locus of Control & & & & & & \\
$\quad$ Internality (Form A) & 6 & 0.70 & 26.79 & 3.60 & 17 & 36 \\
$\quad$ Internality (Form B) & 6 & 0.73 & 26.24 & 3.74 & 17 & 35 \\
$\quad$ Internality (Form C) & 6 & 0.77 & 23.12 & 4.75 & 12 & 34 \\
Health Promotion & & & & & & \\
$\quad$ Physical Activity & 8 & 0.85 & 17.89 & 5.37 & 8 & 32 \\
$\quad$ Nutrition & 9 & 0.80 & 23.96 & 5.14 & 10 & 34 \\
$\quad$ Stress Management & 8 & 0.75 & 19.52 & 4.10 & 12 & 32 \\
$\quad$ Interpersonal Relations & 9 & 0.85 & 27.53 & 5.01 & 18 & 36 \\
$\quad$ Spiritual Growth & 9 & 0.86 & 27.15 & 5.33 & 15 & 36 \\
$\quad$ Health Responsibility & 9 & 0.80 & 21.06 & 4.60 & 9 & 33 \\
$\quad$ Total & 52 & 0.94 & 137.12 & 22.95 & 86 & 191 \\
\hline
\end{tabular}


Table 3

Bivariate Correlations among Key Study Variables

\begin{tabular}{|c|c|c|c|c|c|c|c|}
\hline Variable & 1 & 2 & 3 & 4 & 5 & 6 & 7 \\
\hline \multicolumn{8}{|l|}{ 1. Age } \\
\hline 2. Gender & $-.25 *$ & & & & & & \\
\hline 3. Perceived Limitation & .06 & -.04 & & & & & \\
\hline 4. Future Time Perspective & $-.21 *$ & .05 & $-.30 * *$ & & & & \\
\hline \multicolumn{8}{|l|}{ Internal Health Locus of Control } \\
\hline 5. Form A & -.06 & .05 & .02 & $.21 *$ & & & \\
\hline 6. Form B & -.10 & .07 & .06 & $.25 * *$ & $.61 * *$ & & \\
\hline 7. Form $\mathrm{C}$ & -.06 & -.07 & -.05 & .12 & $.50 * *$ & $.57 * *$ & \\
\hline \multicolumn{8}{|l|}{ Health Promotion } \\
\hline 8. Physical Activity & -.04 & -.11 & $-.23 *$ & $.30 * *$ & $.30 * *$ & .14 & .14 \\
\hline 9. Nutrition & -.07 & $.29 * *$ & $-.23 *$ & $.41 * *$ & $.25 * *$ & .16 & .12 \\
\hline 10. Stress Management & .11 & .15 & -.09 & $.26 * *$ & $.24 *$ & .08 & .13 \\
\hline 11. Interpersonal Relations & .04 & $.21 *$ & -.16 & $.41 * *$ & $.24^{*}$ & .13 & .08 \\
\hline 12. Spiritual Growth & $.20^{*}$ & .12 & $-.23 *$ & $.54 * *$ & $.29 * *$ & .18 & .08 \\
\hline 13. Health Responsibility & .08 & $.21^{*}$ & $-.23 *$ & $.26^{* *}$ & .12 & -.03 & -.19 \\
\hline 14. Total & .07 & .18 & $-.21 *$ & $.47 * *$ & $.31 * *$ & .15 & .08 \\
\hline
\end{tabular}


Table 3 (continued)

\begin{tabular}{|c|c|c|c|c|c|c|c|}
\hline Variable & 8 & 9 & 10 & 11 & 12 & 13 & 14 \\
\hline \multicolumn{8}{|l|}{ Health Promotion } \\
\hline \multicolumn{8}{|l|}{ 8. Physical Activity } \\
\hline 9. Nutrition & $.57 * *$ & & & & & & \\
\hline 10. Stress Management & $.38 * *$ & $.53 * *$ & & & & & \\
\hline 11. Interpersonal Relations & $.31 * *$ & $.51 * *$ & $.62 * *$ & & & & \\
\hline 12. Spiritual Growth & $.39 * *$ & $.55 * *$ & $.70 * *$ & $.73 * *$ & & & \\
\hline 13. Health Responsibility & $.39 * *$ & $.58 * *$ & $.52 * *$ & $.55^{* *}$ & $.57 * *$ & & \\
\hline 14. Total & $.67 * *$ & $.81 * *$ & $.79 * *$ & $.80 * *$ & $.84 * *$ & $.77 * *$ & \\
\hline
\end{tabular}


Table 4

Standardized and Unstandardized Estimates for Preliminary and Hypothesized Models

\begin{tabular}{|c|c|c|c|c|c|c|c|c|}
\hline & \multicolumn{4}{|c|}{ Fully Saturated Model } & \multicolumn{4}{|c|}{ Hypothesized Model } \\
\hline & $\beta$ & $b$ & $\mathrm{SE}(b)$ & $\mathrm{CR}$ & $\beta$ & $b$ & $\mathrm{SE}(b)$ & $\mathrm{CR}$ \\
\hline Future Time Perspective $\leftarrow$ Age & -0.19 & -0.45 & 0.22 & $-2.06^{*}$ & -0.19 & -0.45 & 0.22 & $-2.10^{*}$ \\
\hline Internal Health Locus of Control $\leftarrow$ Age & -0.05 & -0.04 & 0.07 & -0.53 & -0.05 & -0.04 & 0.07 & -0.53 \\
\hline Health Promotion $\leftarrow$ Age & 0.23 & 0.02 & 0.01 & $2.81 *$ & 0.23 & 0.02 & 0.01 & $2.80^{*}$ \\
\hline Future Time Perspective $\leftarrow$ Gender & 0.01 & 0.32 & 2.34 & 0.14 & - & - & - & - \\
\hline Internal Health Locus of Control $\leftarrow$ Gender & 0.05 & 0.36 & 0.75 & 0.48 & 0.05 & 0.36 & 0.75 & 0.48 \\
\hline Health Promotion $\leftarrow$ Gender & 0.20 & 0.19 & 0.07 & $2.56^{*}$ & 0.20 & 0.19 & 0.08 & $2.57^{*}$ \\
\hline Future Time Perspective $\leftarrow$ Perceived Limitation & -0.29 & -0.69 & 0.22 & $-3.20 *$ & -0.29 & -0.69 & 0.22 & $-3.21 *$ \\
\hline Internal Health Locus of Control $\leftarrow$ Perceived Limitation & 0.03 & 0.02 & 0.07 & 0.29 & 0.03 & 0.02 & 0.07 & 0.29 \\
\hline Health Promotion $\leftarrow$ Perceived Limitation & -0.10 & -0.08 & 0.01 & -1.16 & - & - & - & - \\
\hline Health Promotion $\leftarrow$ Future Time Perspective & 0.44 & 0.02 & 0.00 & $5.20^{*}$ & 0.47 & 0.02 & 0.00 & $5.78^{*}$ \\
\hline Health Promotion $\leftarrow$ Internal Health Locus of Control & 0.22 & 0.03 & 0.01 & $2.81 *$ & 0.21 & 0.03 & 0.01 & $2.69 *$ \\
\hline
\end{tabular}

$\mathrm{R}^{2}$ Observed Variables

\begin{tabular}{lll}
\hline Future Time Perspective & 0.005 & 0.005 \\
Internal Health Locus of Control & 0.119 & 0.120 \\
Health Promotion & 0.329 & 0.318 \\
\hline & & $* p<.0$
\end{tabular}


Table 5

Model Fit Indices

\begin{tabular}{|c|c|c|c|c|c|c|}
\hline Model & $\chi^{2}$ & $\mathrm{df}$ & $\mathrm{p}$ & TLI & CFI & RMSEA \\
\hline 1. Baseline - All paths tested & 12.447 & 4 & 0.014 & 0.458 & 0.855 & 0.140 \\
\hline \multicolumn{7}{|l|}{ 2. Dropping non hypothesized paths } \\
\hline FTP $\leftarrow$ Gender & 12.465 & 5 & 0.029 & 0.617 & 0.872 & 0.118 \\
\hline HPLP $\leftarrow$ Perceived Limitation: Hypothesized Model & 13.791 & 6 & 0.032 & 0.667 & 0.867 & 0.110 \\
\hline \multicolumn{7}{|l|}{ 3. Exploratory (dropping non significant HLoC predictors) } \\
\hline HLoC $\leftarrow$ Perceived Limitation & 13.872 & 7 & 0.054 & 0.748 & 0.882 & 0.095 \\
\hline HLoC $\leftarrow$ Gender & 14.084 & 8 & 0.080 & 0.805 & 0.896 & 0.084 \\
\hline HLoC $\leftarrow$ Age & 14.477 & 9 & 0.106 & 0.844 & 0.906 & 0.075 \\
\hline \multicolumn{7}{|l|}{ 4. Exploratory (testing HLPL II subscales) } \\
\hline Health Responsibility & 14.864 & 6 & 0.021 & 0.311 & 0.725 & 0.117 \\
\hline Physical Activity & 15.999 & 6 & 0.014 & 0.280 & 0.712 & 0.124 \\
\hline Nutrition & 14.811 & 6 & 0.022 & 0.547 & 0.819 & 0.117 \\
\hline Spiritual Growth & 13.884 & 6 & 0.031 & 0.746 & 0.898 & 0.110 \\
\hline Interpersonal Relations & 14.539 & 6 & 0.024 & 0.556 & 0.822 & 0.115 \\
\hline Stress Management & 12.571 & 6 & 0.050 & 0.507 & 0.803 & 0.101 \\
\hline
\end{tabular}


Table 6

Multiple Regression Coefficients

\begin{tabular}{lccc}
\hline & $b$ & $(\mathrm{SE}) b$ & $\beta$ \\
\hline Step 1 & & & \\
$\quad$ Constant & 1.76 & 0.50 & \\
Age & 0.01 & 0.00 & .13 \\
Gender & 0.21 & 0.09 & $.22^{*}$ \\
Perceived Limitation & -0.03 & 0.02 & $-.21^{*}$ \\
Step 2 & & & \\
Constant & -0.18 & 0.53 & \\
Age & 0.02 & 0.01 & $.23^{*}$ \\
Gender & 0.19 & 0.08 & $.20^{*}$ \\
Perceived Limitation & -0.01 & 0.02 & -.09 \\
Internal Health Locus of Control & 0.02 & 0.00 & $.22^{*}$ \\
Future Time Perspective & 0.03 & 0.01 & $.43^{*}$ \\
\hline
\end{tabular}

Note: $\mathrm{R}^{2}=.10$ for Step $1, \Delta \mathrm{R}^{2}=.25$ for Step $2(p<.01) .{ }^{*} p<.05$. 


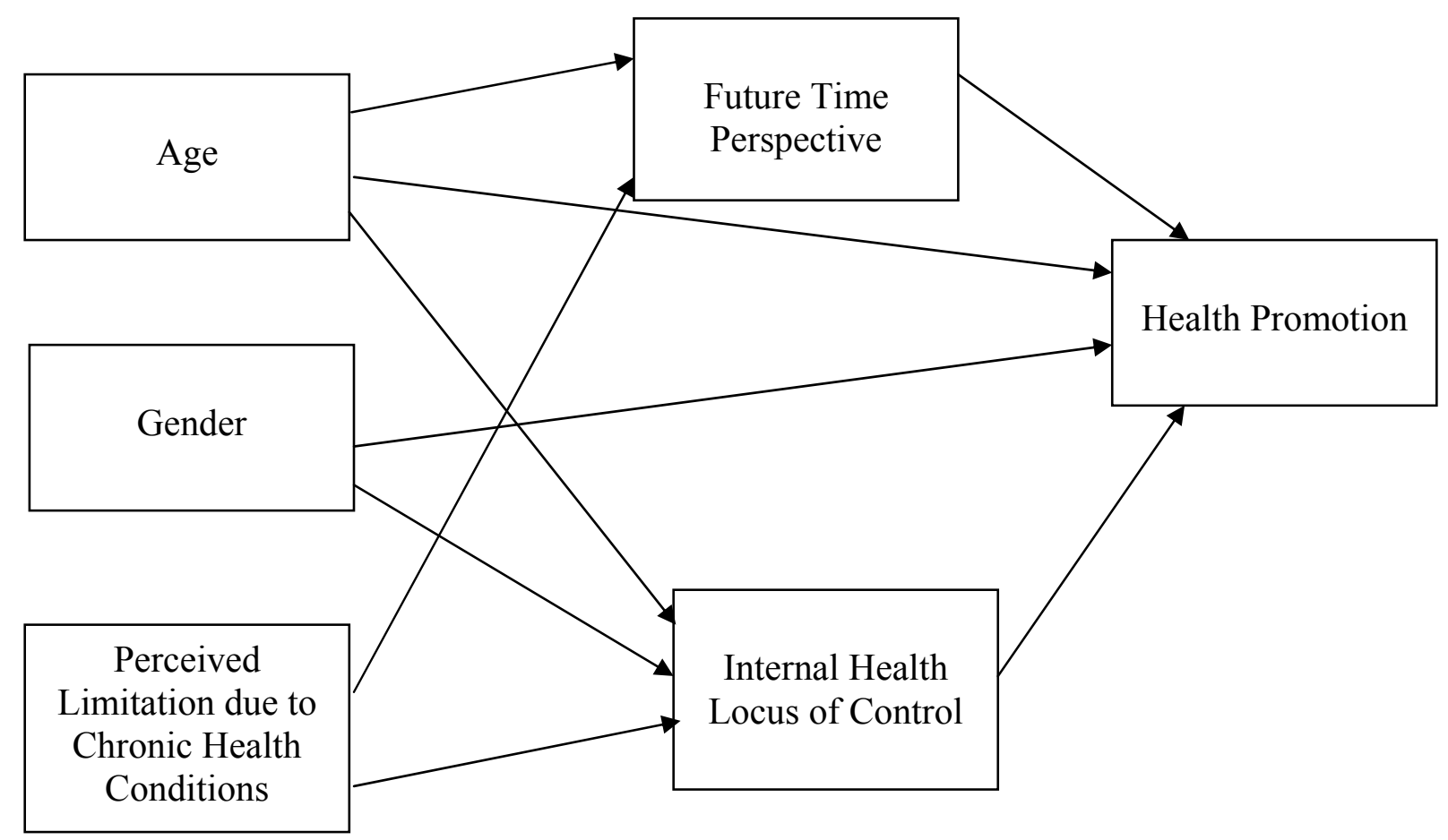

Figure 1. Hypothesized model where the measured, or observed variables, are represented by squares; relations between variables are represented by lines and lack of a line between variables indicates that no relation has been hypothesized. 


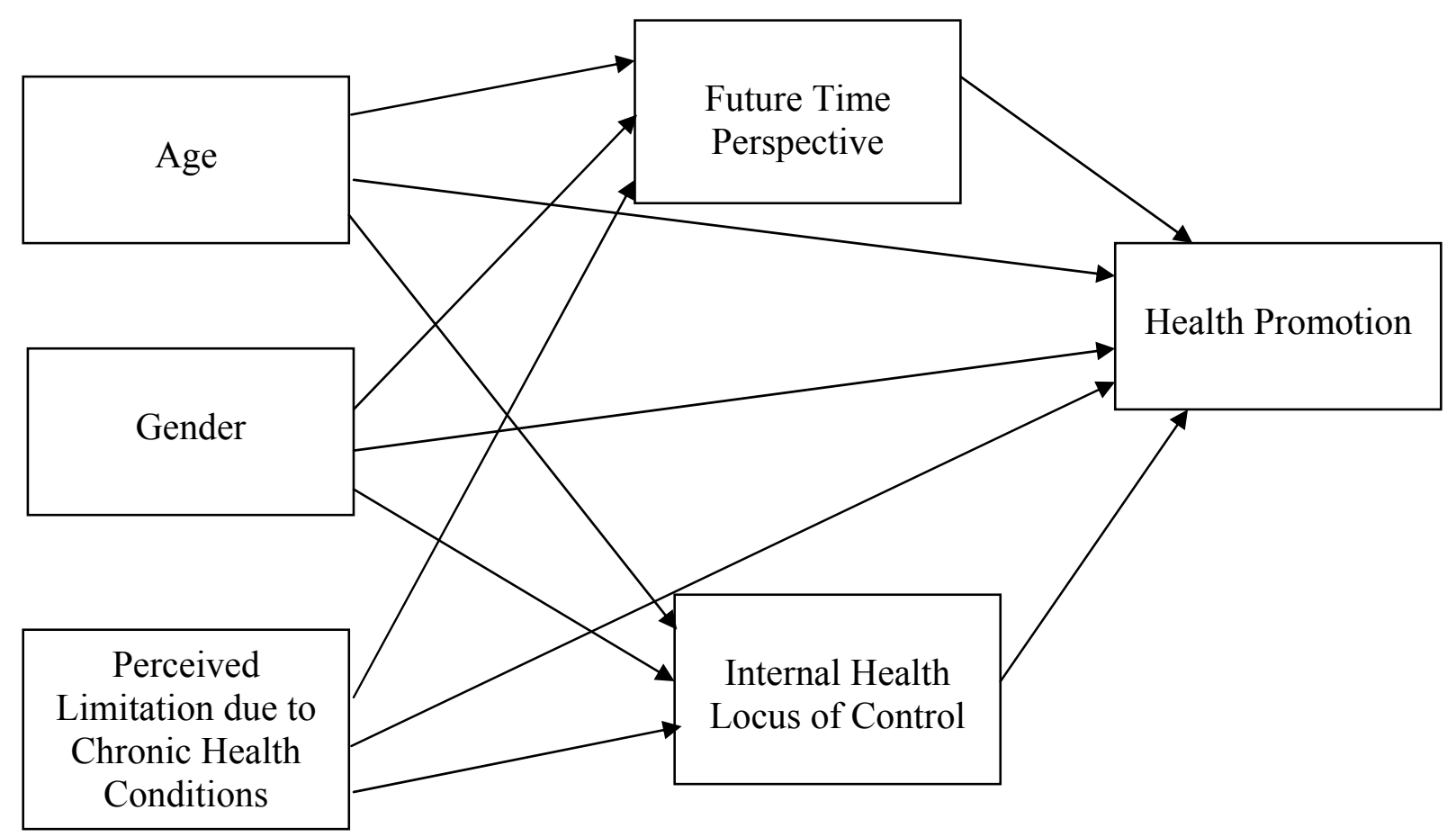

Figure 2. Baseline model, where all paths (hypothesized and not hypothesized) were tested simultaneously. 


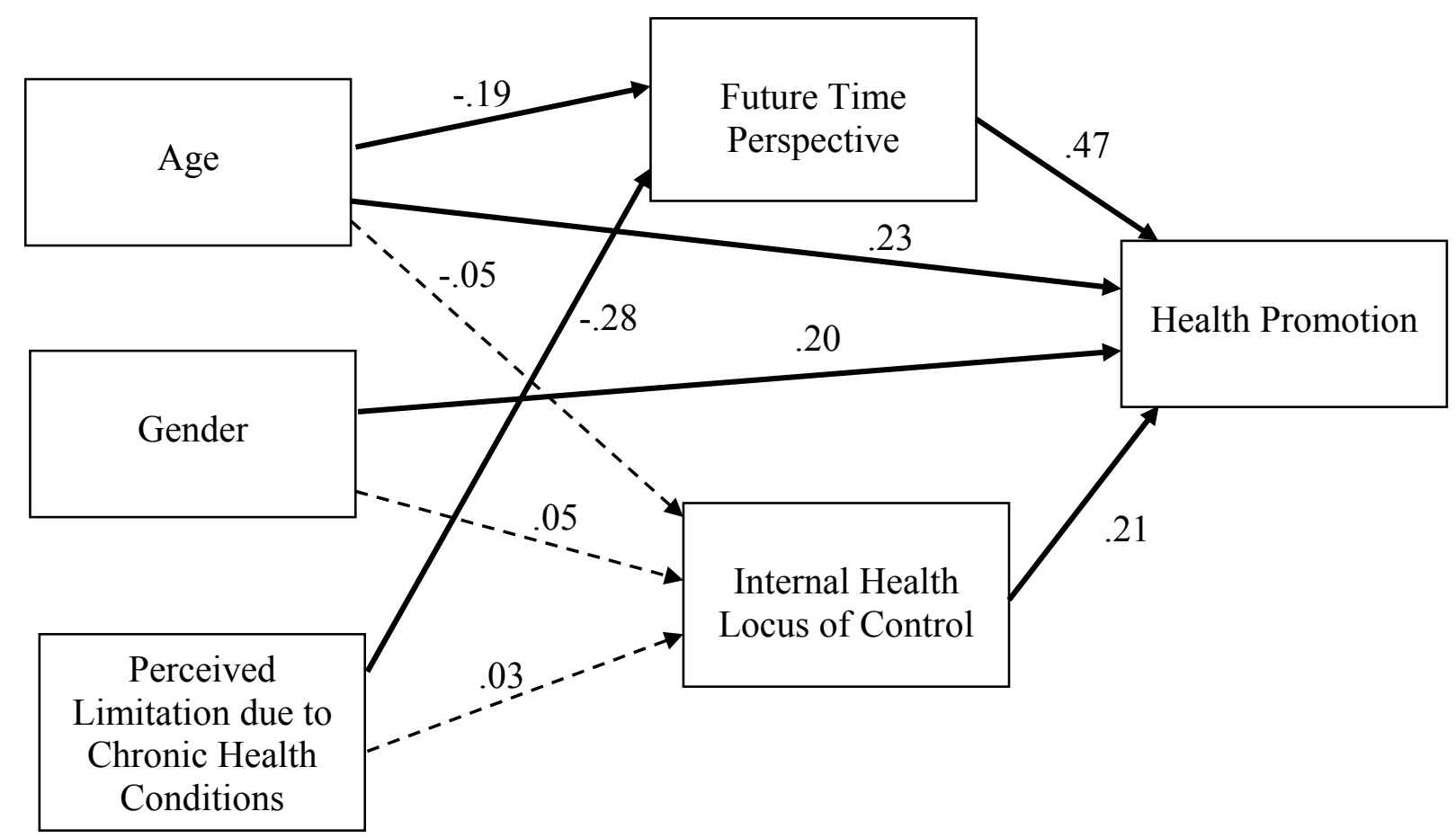

Figure 3. Hypothesized path model, where bolded lines indicate significant paths, dashed lines indicate nonsignificant paths, and lack of a line between variables indicates the path was dropped from model testing. All path estimates are standardized. 


\section{Appendix A: Personal Data Form}

Please answer the following questions as honestly and accurately as possible:

1) Current Age:

2) Sex: __ Male __Female

3) For descriptive purposes, could you please select the ethnicity category to which you most belong:

African American/ Black

Caucasian/ White

American Indian/ Alaskan Native

Asian/ Pacific Islander

Latino/ Hispanic

Other

I do not wish to provide an answer for this question

4) What is your current marital status:

Cohabiting/ Living with Partner (not married)

Married

Widowed

Divorced

Remarried after widowed

Remarried after divorce

Single/ Never married

I do not wish to provide an answer for this question

5) In what state do you currently reside:

6) How many people, including yourself, live in your home:

7) Select the highest level of education you have completed:

Less than $9^{\text {th }}$ grade

$9^{\text {th }}$ to $11^{\text {th }}$ grade

High school diploma

College-Degree

Graduate Degree

I do not wish to provide an answer for this question

8) Total yearly family income:

Less than $\$ 25,000$

$\$ 25,000-\$ 49,999$

$\$ 50,000-\$ 74,999$ 
$\$ 75,000-\$ 99,999$

$\$ 100,000+$

I do not wish to provide an answer for this question

9) How many hours in a typical week do you spend in paid work:

10) How many hours in a typical week do you spend in unpaid volunteer work:

11) Do you currently smoke or use tobacco:

Yes

No

I do not wish to provide an answer for this question

12) Do you wear seat belts regularly:

Yes

No

I do not wish to provide an answer for this question

13) Do you take vitamin supplements:

Yes

No

I do not wish to provide an answer for this question

14) If you take vitamin supplements, which types do you take:

15) How much sleep on average do you get:

16) What is your height (e.g., "5 ft $10 \mathrm{in"):}$

17) What is your weight (in pounds):

18) How many times have you visited the doctor in the last year:

19) I believe my life to be:

Extremely Happy

Very Happy

Somewhat Happy

Average

Somewhat Unhappy

Very Unhappy

Extremely Unhappy 
I do not wish to provide an answer to this question

20) What type of health insurance do you currently have:

Private

Public

None

I do not wish to provide an answer to this question

21) How much do you trust your health care providers:

Not at all

A little

A great deal

I do not wish to provide an answer to this question

22) How easily can you physically access your health care system:

Very easily

Moderately easy

Easy

Moderately hard

Hard

Very hard

I do not wish to provide an answer to this question

23) What types of over the counter medicine do you take (Check all that apply):

Flu medications

Joint supplements

Antacids

Allergy medications

Pain relievers including aspirin

Cold medicine

Anti-diarrhea medicine \& laxatives

Menstrual cycle products for pain and cramp relief

Cough syrup, drops, and throat lozenges

Sinus medications \& nasal sinus sprays

Nicotine gum or patches for smoking cessation

Special ointment or cream for sunburn

BenGay, Tiger Balm, and similar products for muscle or joint pain

First aid cream, calamine lotion, bug bite medication, wart remover treatments

Visine and other such eye products

Suppositories and creams for hemorrhoids

Sleeping aids

Motion sickness pills

I do not wish to provide an answer for this question

24) The following screens are recommended by the U.S. Department of Health and Human Services. Please indicate which of the following screens you have had: 


\begin{tabular}{|l|}
\hline Obesity: Body Mass Index \\
Cholestrol Screening \\
High Blood Pressure \\
Diabetes Screen \\
$\quad$ HIV Screen \\
Other Sexually Transmitted Diseases Screens \\
$\quad$ Skin Cancer Screen \\
$\quad$ Dental Screens \\
$\quad$ Hearing Screen \\
$\quad$ Vision Screen/ Eye Exam \\
$\quad$ Glaucoma Screen \\
\hline
\end{tabular}

25) Have you ever had any of the following screens:

Tobacco Cessation Screens

Breast Cancer Screen

Cervical Cancer Screen

Prostate Cancer Screen

Abdominal Aortic Aneurism Screen

Colorectal Cancer Screen (colonoscopy)

Osteoporosis Screen (bone density tests)

Other screens not listed previously 
Please indicate which conditions you currently have \& how much difficulty each condition causes you.

\section{DO YOU HAVE: $\quad$ In terms of the difficulty it causes you, is it:}

1. Arthritis

2. Heart Trouble

3. Back Problems

4. Breathing Problems

5. Diabetes

6. High Blood Pressure

7. Cancer

8. Glaucoma

9. Cataracts

10. Nervousness/tension

11. Trouble getting or staying asleep

12. Headaches

13. Parkinson's Disease

14. Hardening of the arteries

15. Stomach ulcer

16. Stroke or effects of Stroke

17. Paralysis from any condition other than stroke

18. Circulation trouble in arms or legs

19. Asthma

20. Broken Hip

21. Other broken bones

22. Bladder problems

23. Gall Bladder trouble

24. Kidney trouble

25. Anemia

26. Emphysema

27. Epileptic seizures

28. Pnemonia

29. Serious hearing problems

30. Serious vision problems

31. Other
No Yes

No Yes

No Yes

No Yes

No Yes

No Yes

No Yes

No Yes

No Yes

No Yes

No Yes

No Yes

No Yes

No Yes

No Yes

No Yes

No Yes

No Yes

No Yes

No Yes

No Yes

No Yes

No Yes

No Yes

No Yes

No Yes

No Yes

No Yes

No Yes

No Yes

No Yes
None Mild Moderate Severe

None Mild Moderate Severe

None Mild Moderate Severe

None Mild Moderate Severe

None Mild Moderate Severe

None Mild Moderate Severe

None Mild Moderate Severe

None Mild Moderate Severe

None Mild Moderate Severe

None Mild Moderate Severe

None Mild Moderate Severe

None Mild Moderate Severe

None Mild Moderate Severe

None Mild Moderate Severe

None Mild Moderate Severe

None Mild Moderate Severe

None Mild Moderate Severe

None Mild Moderate Severe

None Mild Moderate Severe

None Mild Moderate Severe

None Mild Moderate Severe

None Mild Moderate Severe

None Mild Moderate Severe

None Mild Moderate Severe

None Mild Moderate Severe

None Mild Moderate Severe

None Mild Moderate Severe

None Mild Moderate Severe

None Mild Moderate Severe

None Mild Moderate Severe

None Mild Moderate Severe 
In order to indicate your agreement with the items, please use the following scale:

\begin{tabular}{|ccccccc|}
\hline $\begin{array}{c}1 \\
\text { Very }\end{array}$ & 2 & 3 & 4 & 5 & 6 & $\begin{array}{c}7 \\
\text { Very } \\
\text { Untrue }\end{array}$ \\
\hline
\end{tabular}

1. Many opportunities await me in the future.

2. I expect that I will set many new goals in the future.

3. My future is filled with possibilities.

4. Most of my life lies ahead of me.

5. My future seems infinite to me.

6. I could do anything I want in the future.

7. There is plenty of time left in my life to make new plans.

8. I have a sense that time is running out.

9. There are only limited possibilities in my future.

10. As I get older, I begin to experience time as limited. 
Instructions: Each item below is a belief statement about your medical condition with which you may agree or disagree. Beside each statement is a scale which ranges from strongly disagree (1) to strongly agree (6). For each item we would like you to circle the number that represents the extent to which you agree or disagree with that statement. The more you agree with a statement, the higher will be the number you circle. The more you disagree with a statement, the lower will be the number you circle. Please make sure that you answer EVERY ITEM and that you circle ONLY ONE number per item. This is a measure of your personal beliefs; obviously, there are no right or wrong answers.

\begin{tabular}{|l|l}
\hline 1=STRONGLY DISAGREE (SD) & 4=SLIGHTLY AGREE (A) \\
2=MODERATELY DISAGREE (MD) & 5=MODERATELY AGREE (MA) \\
3=SLIGHTLY DISAGREE (D) & 6=STRONGLY AGREE (SA) \\
\hline
\end{tabular}

1

If my condition worsens, it is my own behavior which determines how soon I will feel better again.

2 As to my condition, what will be will be.

3 If I see my doctor regularly, I am less likely to have problems with my condition.

4 Most things that affect my condition happen to me by chance.

5 Whenever my condition worsens, I should consult a medically trained professional.

6 I am directly responsible for my condition getting better or worse.

7 Other people play a big role in whether my condition improves, stays the same, or gets worse.

8 Whatever goes wrong with my condition is my own fault.

9 Luck plays a big part in determining how my condition improves.

10 In order for my condition to improve, it is up to other people to see that the right things happen.

11 Whatever improvement occurs with my condition is largely a matter of good fortune.

12 The main thing which affects my condition is what I myself do.

13 I deserve the credit when my condition improves and the blame when it gets worse.

14 Following doctor's orders to the letter is the best way to keep my condition from getting any worse.

15 If my condition worsens, it's a matter of fate.

16 If I am lucky, my condition will get better.

17 If my condition takes a turn for the worse, it is because I have not been taking proper care of myself.

18 The type of help I receive from other people determines how soon my condition improves.

\begin{tabular}{ll|l|l|l|l|l|l|l|l|l|l}
\hline SD & MD & D & MA & SA \\
\hline
\end{tabular}

\begin{tabular}{ll|l|l|l|l|l}
\hline 1 & 2 & 3 & 4 & 5 & 6
\end{tabular}

\begin{tabular}{l|l|l|l|l|l|}
1 & 2 & 3 & 4 & 5 & 6 \\
\hline
\end{tabular}

\begin{tabular}{l|l|l|l|l|l|}
1 & 2 & 3 & 4 & 5 & 6 \\
\hline
\end{tabular}

\begin{tabular}{|l|l|l|l|l|l|}
\hline 1 & 2 & 3 & 4 & 5 & 6 \\
\hline
\end{tabular}

\begin{tabular}{l|l|l|l|l|l|}
1 & 2 & 3 & 4 & 5 & 6 \\
\hline
\end{tabular}

\begin{tabular}{l|l|l|l|l|l|}
\hline 1 & 2 & 3 & 4 & 5 & 6 \\
\hline
\end{tabular}

\begin{tabular}{l|l|l|l|l|l}
1 & 2 & 3 & 4 & 5 & 6
\end{tabular}

\begin{tabular}{l|l|l|l|l|l|}
1 & 2 & 3 & 4 & 5 & 6
\end{tabular}

\begin{tabular}{l|l|l|l|l|l|}
\hline 1 & 2 & 3 & 4 & 5 & 6 \\
\hline
\end{tabular}

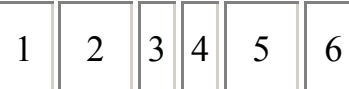

\begin{tabular}{l|l|l|l|l|l}
1 & 2 & 3 & 4 & 5 & 6
\end{tabular}

\begin{tabular}{l|l|l|l|l|l|}
1 & 2 & 3 & 4 & 5 & 6
\end{tabular}

\begin{tabular}{|l|l|l|l|l|l|}
1 & 2 & 3 & 4 & 5 & 6 \\
\hline
\end{tabular}

\begin{tabular}{l|l|l|l|l|l}
1 & 2 & 3 & 4 & 5 & 6
\end{tabular}

\begin{tabular}{l|l|l|l|l|l|}
\hline 1 & 2 & 3 & 4 & 5 & 6 \\
\hline
\end{tabular}

\begin{tabular}{l|l|l|l|l|l|}
1 & 2 & 3 & 4 & 5 & 6
\end{tabular}

\begin{tabular}{l|l|l|l|l|l}
1 & 2 & 3 & 4 & 5 & 6
\end{tabular}

\begin{tabular}{l|l|l|l|l|l}
\hline 1 & 2 & 3 & 4 & 5 & 6
\end{tabular}

Appendix E: Health Promotion Lifestyle Profile II 
This questionnaire contains statements about your PRESENT way of life or personal habits. Please respond to each item as accurately as possible, and try not to skip any item. Indicate the frequency with which you engage in each behavior by circling: 0 (Never), 1 (Sometimes), 2 (Often), or 3 (Routinely)

1. Discuss my problems and concerns with people close to me.

Never

Sometimes

Often

Routinely

2. Choose a diet low in fat, saturated fat, and cholesterol.

Never

Sometimes

Often

Routinely

3. Report any unusual signs or symptoms to a physician or other health professional.

Never

Sometimes

Often

Routinely

4. Follow a planned exercise program.

Never

Sometimes

Often

Routinely

5. Get enough sleep.

Never

Sometimes

Often

Routinely

6. Feel I am growing and changing in positive ways.

Never

Sometimes

Often

Routinely

7. Praise other people easily for their achievements.

Never

Sometimes

Often

Routinely 
8. Limit use of sugars and food containing sugar (sweets).

Never

Sometimes

Often

Routinely

9. Read or watch TV programs about improving health.

Never

Sometimes

Often

Routinely

10. Exercise vigorously for 20 or more minutes at least three times a week (such as brisk walking, bicycling, aerobic dancing, using a stair climber).

Never

Sometimes

Often

Routinely

11. Take some time for relaxation each day.

Never

Sometimes

Often

Routinely

12. Believe that my life has purpose.

Never

Sometimes

Often

Routinely

13. Maintain meaningful and fulfilling relationships with others.

Never

Sometimes

Often

Routinely

14. Eat 6-11 servings of bread, cereal, rice, and pasta each day.

Never

Sometimes

Often

Routinely

15. Question health professionals in order to understand their instructions.

Never

Sometimes 
Often

Routinely

16. Take part in light to moderate physical activity (such as sustained walking 30-40 minutes 5 or more times a week).

Never

Sometimes

Often

Routinely

17. Accept those things in my life that I can not change.

Never

Sometimes

Often

Routinely

18. Look forward to the future.

Never

Sometimes

Often

Routinely

19. Spend time with close friends.

Never

Sometimes

Often

Routinely

20. Eat 2-4 servings of fruit each day.

Never

Sometimes

Often

Routinely

21. Get a second opinion when I question my health care provider's advice.

Never

Sometimes

Often

Routinely

22. Take part in leisure-time (recreational) physical activities (such as swimming, dancing, bicycling).

Never

Sometimes

Often

Routinely 
23. Concentrate on pleasant thoughts at bedtime.

Never

Sometimes

Often

Routinely

24. Feel content and at peace with myself.

Never

Sometimes

Often

Routinely

25. Find it easy to show concern, love, and warmth to others.

Never

Sometimes

Often

Routinely

26. Eat 3-5 servings of vegetables each day.

Never

Sometimes

Often

Routinely

27. Discuss my health concerns with health professionals.

Never

Sometimes

Often

Routinely

28. Do stretching exercises at least 3 times per week.

Never

Sometimes

Often

Routinely

29. Use specific methods to control my stress.

Never

Sometimes

Often

Routinely

30. Work toward long-term goals in my life.

Never

Sometimes 
Often

Routinely

31. Touch and am touched by people I care about.

Never

Sometimes

Often

Routinely

32. Eat 2-3 servings of milk, yogurt, or cheese each day.

Never

Sometimes

Often

Routinely

33. Inspect my body at least monthly for physical changes/danger signs.

Never

Sometimes

Often

Routinely

34. Get exercise during usual daily activities (such as walking during lunch, using stairs instead of elevators, parking car away from destination and walking).

Never

Sometimes

Often

Routinely

35. Balance time between work and play.

Never

Sometimes

Often

Routinely

36. Find each day interesting and challenging.

Never

Sometimes

Often

Routinely

37. Find ways to meet my needs for intimacy.

Never

Sometimes

Often

Routinely 
38. Eat only 2-3 servings from the meat, poultry, fish, dried beans, eggs, and nuts group each day. Never

Sometimes

Often

Routinely

39. Ask for information from health professionals about how to take good care of myself.

Never

Sometimes

Often

Routinely

40. Check my pulse rate when exercising.

Never

Sometimes

Often

Routinely

41. Practice relaxation or meditation for 15-20 minutes daily.

Never

Sometimes

Often

Routinely

42. I am aware of what is important to me in life.

Never

Sometimes

Often

Routinely

43. Get support from a network of caring people.

Never

Sometimes

Often

Routinely

44. Read labels to identify nutrients, fats, and sodium content in packaged food.

Never

Sometimes

Often

Routinely

45. Attend educational programs on personal health care.

Never

Sometimes 
Often

Routinely

46. Reach my target heart rate when exercising.

Never

Sometimes

Often

Routinely

47. Pace myself to prevent tiredness.

Never

Sometimes

Often

Routinely

48. Feel connected with some force greater than myself.

Never

Sometimes

Often

Routinely

49. Settle conflicts with others through discussion and compromise.

Never

Sometimes

Often

Routinely

50. Eat breakfast.

Never

Sometimes

Often

Routinely

51. Seek guidance or counseling when necessary.

Never

Sometimes

Often

Routinely

52. Expose myself to new experiences and challenges.

Never

Sometimes

Often

Routinely 